\title{
Annäherungen an die Jahrhundertenden
}

Wenn wir uns in unserer Vorlesung auf das Ende des 19. Jahrhunderts zubewegen, so dürfen wir zunächst einmal im Überblick festhalten, dass das Jahrhundertende und auch die Jahrhundertwende eine Zeit extremer künstlerischer Kreativität war, in welcher wir einen Höhepunkt literarischen Schreibens in Europa, aber auch in den Amerikas erkennen müssen. Es ist daher nicht einfach, diese Blütezeit panoramatisch darzustellen, da sich in dieser Epoche ungeheuer viele Entwicklungen gleichzeitig anbahnten und ausprägten. Als geokulturellen und politisch-militärischen Hintergrund aber dürfen wir nicht vergessen, dass dies zugleich die dritte Phase beschleunigter Globalisierung war, die zu Beginn des 20. Jahrhunderts einen so hohen Grad an weltweiten Vernetzungen der einzelnen nationalen Volkswirtschaften mit sich brachte, wie er erst wieder in den sechziger Jahren des vergangenen Jahrhunderts erreicht werden konnte. Einher mit dieser beschleunigten Globalisierungsphase ging eine kolonialistische Expansion europäischer Mächte, aber auch der USA sowie - im pazifischen Raum - Australiens, die sich weite koloniale Ergänzungsräume zu sichern suchten. Denn diese dritte Phase beschleunigter Globalisierung war auch die Hochphase des Imperialismus; eine Phase, in welcher sich ganz nebenbei die großen Museen der Kolonialmächte in ungeheurem Maße an den verschiedensten kulturellen Artefakten ihrer Kolonialgebiete bereicherten. Die Schätze dieser Raubzüge stehen in unseren Museen noch immer vor uns.

Die traditionelle Literaturgeschichtsschreibung pflegt vor allem die schriftstellerischen Entfaltungen in den westeuropäischen Literaturen zu betonen; dies ist gewiss nicht falsch, doch verlieren wir auf diese Weise etwa die spanischsprachigen Literaturen aus dem Blick, die beiderseits des Atlantiks eine geradezu explosionsartige Entwicklung durchliefen. Nicht umsonst spricht man in Spanien von einem zweiten Siglo de Oro, einer, silbernen' Jahrhundertwende - und viele der Künstler`innen und ihrer Figuren sind längst Legende. Es gilt daher, im Folgenden die historischen, ökonomischen, politischen und gesellschaftlichen, aber auch die kulturellen und spezifisch literarischen Vorbedingungen und Kontexte dieses Erblühens verschiedenster literarischer Ausdrucksformen im letzten Drittel und insbesondere im letzten Jahrzehnt des 19. Jahrhunderts aufmerksam zu beleuchten.

Wir wollen dabei ebenso die Lyrik, den Roman, die Erzählung, den (philosophischen) Essay wie auch die Beziehungen zwischen verschiedenen Literaturen, Gattungen und künstlerischen Ausdrucksformen (insbesondere zwischen Literatur und Malerei) analysieren und zugleich die transatlantischen Beziehungen nicht aus den Augen verlieren, bildet doch das Pendeln zwischen zwei Welten das Rückgrat unserer Vorlesung. So sollen die für die unterschiedlichen ,Jahrhundert- 
wenden' in Europa und Lateinamerika jeweils charakterisierenden Verfahren und Gestaltungsformen einer vergleichenden Perspektive unterworfen werden, wobei stets unser eigener Standpunkt in den ersten Dekaden eines neuen Jahrtausends in die Reflexion miteingehen wird. Keine eben kleine Aufgabe für eine Vorlesung, die sich ein furioses Finale vorgenommen hat und sich lustvoll darauf einlässt.

Versuchen wir also zunächst, bei unserer Annäherung an das Jahrhundertende, das „Fin de siècle“, das „Fin de siglo“ zunächst einen gerafften Überblick $\mathrm{zu}$ geben, bevor wir uns auf Einzelstudien einlassen, welche wie stets in dieser Vorlesung die spezifischen Schreibverfahren nicht selten in einem Close Reading beleuchten sollen und gleichsam Probebohrungen darstellen, die uns aus den Zwängen einer Literaturgeschichtsschreibung entlassen! Doch da uns Raum und Zeit in dieser Vorlesung fehlen, soll sich diese Annäherung, dieser Überblick auf das Nötigste beschränken. Mir kommt es nicht darauf an, Sie auf eine Geschichtsdeutung, auf einen Geschichtsverlauf einzuschwören; vielmehr erscheint es mir als unverzichtbar, Ihnen stets auch Gegenbeispiele für eine Entwicklung zu präsentieren, so dass Sie ein lebendiges Bild jener Zeit gewinnen können. Faszinierend ist diese literarisch-künstlerische Epoche ohne Frage!

Dass mit dem Jahrhundertende auch Endzeitvorstellungen verbunden waren, auf die wir an unterschiedlichsten Stellen stoßen werden, ist keine neue Erkenntnis: Auch am Ausgang des 20. Jahrhunderts ließen sich derartige Tendenzen beobachten. Und dass in diesem Zusammenhang Überlegungen erblühten, welche die Literaturen an ein Ende gekommen sahen, war gerade mit Blick auf das Fin de siècle nicht verwunderlich. Gewiss ist dieser Endzeitwahn auch keine Vorstellung, die sich ausschließlich während des Jahrhundertendes gezeigt hätte. Vieles von dem, was wir am Ende des 19. Jahrhunderts finden, hat sehr weitreichende historische und kulturelle Bezüge, welche nicht selten noch einmal die Entwicklungen des gesamten Jahrhunderts thematisieren.

So möchte ich Ihnen vorab, bevor wir uns also hinein in dieses Jahrhundertende stürzen, ein besonders schönes Beispiel jener Rede vom Ende der Literaturen geben, das in Form eines medialen Geredes noch immer in den USA populär ist. Das Ende der Literatur: Ich habe noch nie an eine solche Vorstellung geglaubt, denn es wird stets Menschen geben, die ohne eine große Produktionsfirma, ohne große Gerätschaften mit einem Stift einer weißen Seite Papier gegenübersitzen! Gleichviel, ob es sich dabei um eine Tontafel, um Schildkrötenpanzer, um Papyrus-Rollen, um Pergament oder um Bildschirme, Screens auf Ihrem Smartphone oder um Leuchtdioden handelt. Mir scheint mithin die Vorstellung lächerlich, dass wir uns heute am Ende einer vieltausendjährigen Geschichte in den verschiedensten Sprachen, Kulturen und Zeitaltern befänden, bloß weil in den USA ein kleines Häuflein von Kultur- und Literaturtheoretikern das Ende der Literatur proklamiert hat. Literatur hat sich, gleich auf welchem materiellen Support, stets an 
die vorhandenen Medien angepasst und ihre spezifischen Möglichkeiten genutzt, ohne damit große Industrien zu bewegen oder Produktionsfirmen in Hollywood oder Disneyland zu benötigen.

Schauen wir uns kurz ein literarisches Beispiel für einen derartigen Diskurs an und betrachten wir zugleich sein Gegengift! Mitte des 19. Jahrhunderts schreibt der französische Schriftsteller Gustave Flaubert von seiner berühmten Orientreise aus Jerusalem am 4. September des Jahres 1850 an seinen Freund, den eher zweitklassigen Schriftsteller Louis Bouilhet ins heimatliche Frankreich - und wir hören hier jenen wachen, kritischen, ungeheuer hartnäckig nach der Verwirklichung seiner kreativen Möglichkeiten suchenden Geist, der nichts so sehr hasste wie die Dummheit:

Ja, die Dummheit besteht darin, Schlussfolgerungen ziehen zu wollen. Wir sind ein Faden und wir wollen das Gewebe kennen. Das läuft auf die ewigen Diskussionen über die Dekadenz der Kunst hinaus. Man verbringt heute seine Zeit, sich zu sagen: Wir sind vollständig am Ende, wir sind zum letzten Punkt gelangt usw. Welcher etwas überlegenere Geist, angefangen bei Homer, hätte Schlussfolgerungen gezogen? Begnügen wir uns mit dem Bild, das ist ebenso gut. Und dann, mein armer Alter: Gibt es nicht die Sonne (selbst die Sonne von Rouen)? Den Geruch gemähten Heus, die Schultern der Frauen von dreißig Jahren, das alte Buch vor dem Kamin und das chinesische Porzellan? Wenn alles tot ist, wird die Phantasie aus den Fasern des Holundermarks und den Scherben des Nachttopfs wieder neue Welten bauen. Ich bin sehr neugierig auf dieses ordentliche chinesische Märchen. Diese Reise wird mich über die Trauer der Rückkehr hinwegtrösten. Ich kann Dir etwas Ermutigendes sagen, was zudem das Verdienst hat, aufrichtig zu sein: Was die Natur betrifft, kannst du kühn vorwärtsgehen. Alles, was ich hier sehe, finde ich wieder: nur von den Städten, den Menschen, den Gebräuchen, Kostümen, Geräten, den Dingen der Menschen also, kannte ich die Details nicht genau. Ich hatte mich nicht getäuscht: Wer Desillusionen erlebt, ist ein armer Teufel. Es gibt Landschaften, durch die ich schon gekommen bin, das ist gewiss. Merk' Dir also dies als Regel: Sie ist das Ergebnis einer genauen Erfahrung, der seit zehn Monaten nichts widerspricht. Wir sind zu weit in der Kunst fortgeschritten, um uns noch über die Natur zu täuschen, also: voran! ${ }^{1}$

Auf eine wunderbare Weise tritt in dieser Passage der Diskurs der Dekadenz im Mund der anderen - und der Diskurs eines sich keiner Täuschung hingeben wollenden Autors zusammen; denn wir haben es mit Flaubert zu tun, jenem Schriftsteller, der wie kein anderer die „éternelle misère de tout“ und die ungeheure Dummheit, die „bêtise“ seiner Zeitgenossen angeprangert hat. Er ist sich der Existenz dieses allgemeinen, dieses sogar dominierenden Diskurses bewusst

1 Flaubert, Gustave: à Louis Bouilhet. Dams, 4 septembre 1850. In: Ders.: Euvres complètes de Gustave Flaubert; Bd. 13-16: Correspondance 1850-1859. Paris: Société des études littéraires françaises. Éditeur scientifique 1974-1976, S. 74-79, hier 76 f. 
und hält sogleich das Gegengift bereit: die Präsenz der Dinge, die Präsenz der Landschaften, die Anmut menschlicher Körper, die Schönheit der Bücher, der kleinen Szenerien, die sich jemand ausgedacht hat. Ist hierin nicht die Schönheit des Lebens in wenigen Worten erfasst?

Es geht nicht um den Widerstand, sondern um eine fundamentale Widerständigkeit der Kunst, die allem widersteht - auch dem Tod des einzelnen Individuums. Denn ist nicht die Kunst, wie Flaubert an anderer Stelle sagt, noch die angenehmste aller Lügen, mit denen wir tagtäglich konfrontiert werden, so dass es uns den Ekel und die Scham auf unsere Wangen, auf unsere Gesichter treibt? Es gibt eine Antwort darauf, die das Demiurgische meint, das Welten-Schaffende, den kreativen Zwang, etwas dagegensetzen zu können gegen die ewige Misere des ganzen Lebens. Nein, Flaubert hat nicht kapituliert, er hat sich keinem Dekadenzdiskurs hingegeben, obwohl er ein niemals Getäuschter und damit auch nicht Enttäuschter war. Er gab sich den Täuschungen nicht hin, um sein eigenes Programm einer künstlerischen Kraft, einer ästhetischen Widerständigkeit zu verwirklichen: immer voran, ohne auch nur im Geringsten dem Fortschrittsgedanken in Kunst und Literatur zu verfallen.

Der Begriff „Fin de siècle“ sollte nicht terminologisch eng ausgelegt werden, gehen Jahrhundertende und Jahrhundertwende doch lückenlos ineinander über. Ich möchte in dieser Vorlesung zu den Literaturen des 19. Jahrhunderts allerdings das Fin de siècle mit dem Jahrhundertende enden lassen, da meine Vorlesung zum 20. Jahrhundert noch vor der Jahrhundertwende mit Alfred Jarrys Ubu Roi einsetzt ${ }^{2}$ und - wie wir noch sehen werden - es gerade in Lateinamerika als sinnvoll erscheint, mit dem Epochenjahr 1900 abzuschließen. Dabei steht außer Frage, dass ich keineswegs der Zahlenmagie erliegen will, dass ich vielmehr von Kontinuitäten und schleifenden Schnitten ausgehe, welche gerade den Ausgang des 19. Jahrhunderts charakterisieren und so spannend machen.

Es gibt gute Gründe dafür, das Jahrhundertende nicht als Jahrhundertwende zu deuten und nicht bis zum Beginn des Ersten Weltkriegs auszudehnen, wodurch das letzte Drittel des 19. Jahrhunderts mit den ersten anderthalb Jahrzehnten des 20. Jahrhunderts ein Kontinuum bilden würde. Denn die historischen Avantgarden beginnen lange vor dem Ersten Weltkrieg und weisen unverkennbar auf verschiedenste literarische Vorläufer, die sich noch im 19. Jahrhundert ansiedeln. Als der Erste Weltkrieg begann, standen die historischen Avantgarden in voller Blüte: Die italienischen Futuristen etwa genossen - wie auch ein Gabriele d'Annunzio - den Ausbruch des Krieges als künstlerisches Spektakel. Trennen wir

2 Vgl. hierzu Band 3 der „Aula“-Reihe Ette, Ottmar: Von den historischen Avantgarden bis nach der Postmoderne, S. 110-153. 
folglich besser das 19. relativ scharf vom 20. Jahrhundert ab; und dies im vollen Bewusstsein aller Kontinuitäten, die in beiden Welten das Fin de siècle als künstlerische Übergangsepoche erscheinen lassen! Dabei denke ich nicht nur an den bereits erwähnten Alfred Jarry, sondern auch an französische Dichter wie Lautréamont oder vor allem Arthur Rimbaud. Nach dem dichterischen Verstummen Rimbauds begab sich der noch junge Franzose auf eine unstete Wanderschaft, die in ihrer außereuropäischen Dimension nicht von ungefähr von den historischen Bedingungen und Infrastrukturen der dritten Phase beschleunigter Globalisierung begünstigt wurde - einschließlich jener Waffenlieferungen nach Äthiopien, an denen der zu Geld gekommene Rimbaud beteiligt war.

Stärker als je zuvor sind die Literaturen am Ende des 19. Jahrhunderts miteinander verwoben und vernetzt. Dies gilt nicht nur für diejenigen Europas, sondern auch bezüglich der transatlantischen Verknüpfungen, welche sich in diesem Zeitraum verstärkt herausbildeten. Das bedeutet, dass eine nationalphilologische Herangehensweise hochgradig künstliche und nicht sachgemäße Abtrennungen vornehmen würde, welche den internationalen wie intertextuellen Vernetzungsstrukturen nicht einmal im Ansatz gerecht werden könnten: Eine transareale Vorgehensweise wie die in dieser Vorlesung gewählte ist folglich notwendig. Wie wäre sonst ein Gabriele d'Annunzio zu verstehen, der wie Filippo Tommaso Marinetti nicht nur von Italien aus zu begreifen ist, sondern gerade in Frankreich eine gewichtige Rolle im literarischen Feld spielte? Und wie wäre ein Rubén Darío zu begreifen, wenn wir ihn nur in Nicaragua oder später in Chile und Argentinien situierten, nicht aber seine wichtige transatlantische Rolle in Spanien, aber auch in Frankreich und Italien berücksichtigten?

Darüber hinaus lässt sich mit dem Verweis allein auf die historischen Koordinaten und Geschehnisse nicht begründen, wie die jeweiligen finisekulären Ausprägungsformen in Literatur und Kunst entstanden. Denn es gab nicht nur ein Fin de siècle mit dekadentem, larmoyantem oder geschichtspessimistischem Unterton in Frankreich oder Spanien, wo man nach den Niederlagen im Preußisch-Französischen Krieg oder in den Kriegen um die letzten Kolonialgebiete in Amerika gute Gründe dafür hatte, dunkle Vorahnungen in den Literaturen wie in den Künsten zu pflegen. Auch in Ländern wie Deutschland oder Italien machte sich ein Geschichtspessimismus breit, obwohl wenige Jahrzehnte zuvor ein lange Zeit behinderter Nationenbildungsprozess geglückt war, der mit starken wirtschaftlichen Erfolgen und zeitweise sogar mit einer dezidierten kolonialen Expansion dieser Länder einherging. Ähnliches ließe sich durchaus auch für eine Reihe von Ländern in Lateinamerika sagen.

Es bliebe weitgehend unerklärlich, warum düstere Stimmungen in derartigen soziokulturellen und politischen Zusammenhängen aufkamen, wenn wir die spezifische Geschichte des Fin de siècle nicht als die Ausprägung eines international, 
ja weltweit miteinander vernetzten intertextuellen Geschehens begreifen würden, das seinen eigenen Gesetzlichkeiten und Logiken folgte. So wäre es absurd, das französische Fin de siècle ohne Richard Wagner, ohne Friedrich Nietzsche, ja ohne Arthur Schopenhauer zu betrachten, so wie es verfehlt wäre, José Enrique Rodó allein vor dem Hintergrund seines Heimatlandes Uruguay zu begreifen. Selbst eine durchaus legitime Spezialisierung auf eine bestimmte Tradition, Nation oder Nationalphilologie bedarf einer fundamentalen Berücksichtigung der jeweiligen internationalen Vernetzungen. Und schon Erich Auerbach hatte zu diesem Problem, das nicht nur für eine zu schaffende „Philologie der Weltliteratur“ bestand, bereits 1952 das Notwendige gesagt: „Und doch wird es immer unbefriedigender, sich nur mit einem Spezialgebiet zu befassen; wer heute etwa ein Provenzalist sein will und nichts anderes beherrscht als die einschlägigen Teile der Linguistik, der Paläographie und der Zeitgeschichte, der ist kaum auch nur noch ein guter Provenzalist.“3 ${ }^{3}$ Speziell intertextuellen Bezugssystemen und Fragestellungen ist daher ein besonderes Gewicht einzuräumen.

Intertextualität ist eine Grundbedingung von Literatur überhaupt. Man könnte sie als das schlagende Herz der Literaturen der Welt wie von Literatur überhaupt bezeichnen. Doch es gibt Phasen verstärkter und Phasen schwächerer Intertextualität - und wie Sie schon erwarteten, gehört das Fin de siècle ohne jeden Zweifel $\mathrm{zu}$ jenen einer ganz besonderen intertextuellen Intensität; und diese Intensität bedeutet zugleich eine stärkere wechselseitige Vernetzung.

Dabei dürfen wir diese Intertextualität, also die Bezugnahme auf Texte einer anderen Autorin oder eines anderen Autors, nicht unabhängig von der Frage der Macht behandeln. Wenn ich eine intertextuelle Beziehung zu einem anderen Text herstelle, dann ist dieser Text abwesend, es sei denn, ich zitiere aus ihm, wobei es diese Passagen dann sind, welche in meinem Text erscheinen und die ich mir folglich angeeignet habe. Damit ist eine gewisse Macht, ja Gewalt über den abwesenden Text verbunden, den ich in meine eigenen Texte integrieren kann. Nicht umsonst besitzt das schöne spanische Wörtchen „citar“ in der Tauromachie die Bedeutung des Provozierens und Herbeirufens der Bestie: Es geht darum, den Stier (oder auch das verbündete, liebgewonnene Tier) an eben jener Stelle zu platzieren, an der dies für die eigenen Zwecke und Ziele am günstigsten ist.

Damit ist keineswegs nur eine individuelle Dimension gemeint: Jenseits von Phänomenen der Paratextualität, der wir unsere Aufmerksamkeit schon

3 Auerbach, Erich: Philologie der Weltliteratur. In: Weltliteratur. Festgabe für Fritz Strich. Bern 1952, S. 39-50; wieder abgedruckt in Auerbach, Erich: Gesammelte Aufsätze zur romanischen Philologie. Herausgegeben von Fritz Schalk und Gustav Konrad. Bern - München: Francke Verlag 1967, S. 301-310, hier S. 303. 
oft zuwandten, und der Architextualität, welche die Filiationen von Gattungen betrifft, sind Konstituierungsformen eines literarischen Raumes gerade im Zusammenspiel zwischen beiden Welten von großer Bedeutung. Unter einem literarischen Raum verstehe ich die innerliterarische, also durch einen Text gleichviel ob Roman, Erzählung, Theaterstück oder Gedicht - selbst konstituierte Präsenz von Bezugstexten aus unterschiedlichen Literaturen, die auf explizite, aber auch auf implizite Weise diesen (Bewegungs-)Raum konfigurieren. Wir hatten am mexikanischen Schelmenroman mit der besonderen Bedeutung der spanischen und französischen Literatur, sowie am argentinischen Roman mit der Relevanz englischer und französischer Romantexte bereits durchgespielt und verstanden, wie wichtig die Bezugnahme auf bestimmte Nationalliteraturen gerade in den Amerikas ist. Aber auch eine Germaine de Staël hatte mit ihrer starken Einbeziehung deutschsprachiger Texte den Ärger nicht nur der französischen Kritik, sondern auch von Napoleon höchstselbst provoziert, verstand man doch diese Bezugnahme als Aufwertung der kleinen deutschsprachigen Länder und als implizit politischen Akt.

Der durch die expliziten oder impliziten Bezugnahmen konfigurierte literarische Raum sagt uns zunächst einmal etwas darüber aus, welche literarischen Vorlieben bestimmte Figuren oder Protagonisten innerhalb eines gegebenen Romans haben: So war beispielsweise die schöne María in José Mármols gleichnamigem Roman eine bewundernde Leserin der englischen und französischen Romantik gewesen. Der literarische Raum kann uns darüber hinaus unterschiedlichste Hinweise auf für unsere Interpretation überaus wichtige Fragestellungen geben. Wir werden sehen, dass sich im letzten Drittel des 19. Jahrhunderts - also während der dritten Phase beschleunigter Globalisierung - erneut die geokulturellen und geoliterarischen Bezugnahmen zwischen beiden Welten verändern, und damit jene Asymmetrie der Beziehungen, ${ }^{4}$ welche sich seit dem Beginn der Kolonialzeit herausbildete.

Im Fin de siècle kommt den Beziehungen zwischen den Künsten, zwischen Dichtung und Malerei, zwischen Musik und Roman im Zeichen synästhetischer Konzeptionen umfassender Gesamtkunstwerke eine große Bedeutung zu. Die Literaturen des Jahrhundertendes und der Jahrhundertwende sind Perioden einer intensiven Inter- und Transmedialität, die wir auf den folgenden Seiten wiederholt verfolgen werden. Gerade in den Literaturen des Fin de siècle konstatieren wir eine Bewegung hin zu anderen künstlerischen Ausdrucksmedien, welche

4 Vgl. Ette, Ottmar: Asymmetrie der Beziehungen. Zehn Thesen zum Dialog der Literaturen Lateinamerikas und Europas. In: Scharlau, Birgit (Hg.): Lateinamerika denken. Kulturtheoretische Grenzgänge zwischen Moderne und Postmoderne. Tübingen: Gunter Narr Verlag 1994, S. $297-326$. 
die Sprachen und Wirkungen der Literatur ergänzen, komplettieren oder radikal erneuern können. Anfänge hierzu hatten wir in Arthur Rimbauds Gedicht Voyelles bereits gesehen. $\mathrm{Zu}$ jener Zeit kam der Konkurrenz oder dem Wettstreit zwischen den Künsten, insbesondere dem Kampf zwischen Literatur und Malerei um die Vorherrschaft zwischen unterschiedlichen künstlerischen Ausdrucksmedien, eine besondere Relevanz und künstlerisch-literarische Bedeutung zu. So könnte man die Literaturen des Fin de siécle als jene betrachten, die sich zunehmend der Tatsache bewusst wurden, dass die Literatur nicht mehr selbstverständlich die vorherrschende unter den verschiedenen künstlerischen Praktiken sein musste. Im Umkehrschluss ließe sich damit die epochenspezifische Offenheit der Literatur für die unterschiedlichsten Künste begründen.

Neben den sicherlich vorherrschenden ikonotextuellen Beziehungen, die sich zwischen Literatur und Malerei herstellen, gibt es - zumeist vernachlässigt, aber nicht weniger wichtig - die phonotextuellen Relationen, die sich zwischen Literatur und Musik etablieren; etwa die besondere Bedeutung, welche der Musik eines Richard Wagner oder Hector Berlioz zukam. Hierfür gab es im Fin de siècle eine spezifische Sensibilität. Weder die ikonotextuellen noch die phonotextuellen Beziehungen sind in den Literaturen der Welt neu, doch gewinnen sie in den Literaturen des ausgehenden 19. Jahrhunderts eine solche Stärke und Intensität, wie sie zuvor nur höchst selten zu beobachten war. Dass wir es in diesem intermedialen Bereich - denken wir nur an Richard Wagners Vorstellung vom Gesamtkunstwerk - mit einem Erbe der Spätromantik zu tun haben, versteht sich von selbst, stellt aber diese Epoche zugleich auch in einen kultur- und kunstgeschichtlichen Rahmen, auf den wir noch vielfach rekurrieren werden.

Entschuldigen Sie nun bitte ein kurzes transmediales Intermezzo! Es ist schade, dass ich Ihnen an dieser Stelle der Vorlesung in Buchform nicht die ersten Bilder von Richard Strauss' Oper Die Liebe der Danae einspielen kann, gäben uns doch diese Klangbilder aus der Feder eines der wichtigsten Komponisten des Fin de siècle gleichsam ein Soundscape für diesen Teil unseres Durchgangs. Dessen erste Oper Guntram wurde 1894 uraufgeführt und demonstrierte bereits zum damaligen Zeitpunkt jene Klangbreite und Musik, die uns nun zumindest imaginär begleiten soll. Die Entstehungszeit von Die Liebe der Danae geht in die dreißiger Jahre des 20. Jahrhunderts zurück, doch eben deshalb möchte ich Ihnen gleichsam prospektiv diese künftigen Klangbilder vor das innere Ohr zaubern. Gleichzeitig zu dieser Szenerie des goldenen Hochkapitalismus in Strauss' Oper sollten Sie sich die Danae von Gustav Klimt vor Augen führen, mit jener erotisch aufgeladenen Unschuld, in welcher sie das 1907 entstandene Gemälde zeigt. Damit haben Sie nun wesentliche Ingredienzien jener intensiv aufgeladenen literarischen Szenerien erhalten, durch welche wir in den kommenden Kapiteln unter anderem streifen werden. Und damit ist dieses Intermezzo, das Sie mir bitte 
nachsehen, auch schon wieder vorbei! In meiner ersten Potsdamer Vorlesung zum Fin de siècle hatte ich dazu noch Räucherkerzen entzündet ...
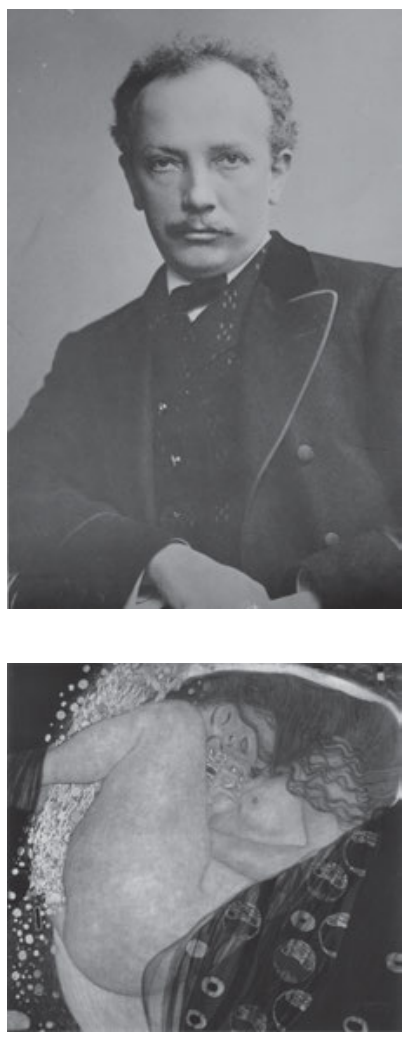

Abb. 69: Richard Strauss

(München, 1864 - Garmisch-Partenkirchen, 1949).

Abb. 70: „Danaë“, Öl auf Leinwand von Gustav Klimt, 1907.

Wer sich mit den Literaturen des Fin de siècle beschäftigt, muss sich notwendig mit den Beziehungen zwischen Literatur und Philosophie, aber auch mit jenen zwischen Literatur und Psychologie beziehungsweise Psychoanalyse auseinandersetzen. Zum einen ist dabei Friedrich Nietzsche ein unverzichtbarer Begleiter, liegt das philosophische Werk dieses Philologen doch am Schnittpunkt von philosophischer Begrifflichkeit und literarischer Polysemie. Zum anderen aber ist es Sigmund Freud, dessen Psychoanalyse zwar erst die nachfolgenden Generationen, insbesondere die Surrealisten beeinflusst und bisweilen sogar geprägt hat, der aber umgekehrt gerade die Literatur als ein Hilfsmittel erkannt hatte, dem er Impulse und Anregungen für die wissenschaftliche Erforschung des psychischen Apparats entnehmen konnte. Dass die Veröffentlichung von Sigmund Freuds Traumdeutung genau in das Jahr 1900 fällt, ist ein Faktum, das nicht weniger wichtig für die Literaturen am Ende des Jahrhunderts ist als die Tatsache, dass 
im selben Jahr José Enrique Rodós Ariel vorgelegt wurde. Dass übrigens beide Publikationen bereits 1899 fertiggestellt wurden, sich aber mit der ersten Jahreszahl des neuen Jahrhunderts schmücken wollten, mag nicht nur ein Beleg für die Zahlenmagie, sondern auch für den Glauben der Verfasser an die epochale Bedeutung ihrer jeweiligen Werke sein.

Eine der notwendig bei der Betrachtung der Literaturen am Ausgang des 19. Jahrhunderts sich stellenden Grundfragen betrifft das Verhältnis zwischen Moderne und Fin de siècle. In den unterschiedlichsten Gesellschaften jener Zeit machen sich ungeheure Modernisierungsprozesse bemerkbar, die im letzten Drittel des neunzehnten Jahrhunderts im Kontext der sich ausprägenden Phase beschleunigter Globalisierung zur weitgehenden Umgestaltung der Lebensverhältnisse zahlloser Menschen in beiden Welten führten. In welchem Verhältnis stehen diese sozioökonomischen Modernisierungsprozesse zum einen mit der Epochenfrage der Moderne und den unterschiedlichen Formen eines ästhetischen und literarischen Modernismus, der sich ebenso in England wie in Katalonien oder Frankreich, in Argentinien wie in Uruguay oder Mexiko, ebenso im Bereich der Ästhetik wie der Religion Stimme und Gewicht während jener Jahrhundertwende verschafft? Oder anders gefragt: Wie lassen sich diese modernistischen literarischen Strömungen und Tendenzen, die sich auf den gesamten Bereich der Kultur ausweiteten, in Verbindung bringen mit dem Projekt der (europäischen) Moderne im Sinne eines Jürgen Habermas und den Konzeptionen einer literarischen und ästhetischen Moderne, wie sie sich im Entwurf bereits in den Texten Baudelaires findet? Auch hierauf wollen wir eine Antwort $\mathrm{zu}$ geben versuchen, die sich der Tatsache bewusst ist, dass allein nationalphilologische Analysen auf derlei Fragen keine befriedigenden Antworten geben können. Um es deutlich zu sagen: Es geht an dieser Stelle nicht um den Beginn der Moderne, den wir im letzten Drittel des 18. Jahrhunderts situierten, sondern um die verschiedenen Ausprägungsformen der Moderne in einem Sinne, der uns von unterschiedlichen Modernen im Plural sprechen lässt!

Auf den ersten Blick konträr zu diesem Modernisierungsschub gerade in den romanischen Ländern weltweit steht eine Stimmung der Dekadenz, die sich gegen Jahrhundertende in vielen Ländern der Romania breitmachte - und wie alle meine Vorlesungen geht auch diese davon aus, dass es eine ,special relationship zwischen den verschiedensten romanischen Literaturen der Welt und somit spezifische Übertragungswege gibt. Es bedarf keines sehr vertieften Studiums des Fin de siècle, um jenen Basso continuo herauszuhören, der in besonderem Masse in den romanischen Ländern Symptome einer Endzeitstimmung und Endzeiterwartung ausmacht. Im Verlauf des neunzehnten Jahrhunderts hatte der Fortschrittsoptimismus, den das ausgehende 18. Jahrhundert in das neue Saeculum hinübergetragen hatte, empfindliche Dämpfer erhalten, verlief doch die Geschichte 
keineswegs so geradlinig und progressiv, wie man sich dies am Ausgang des Jahrhunderts der Aufklärung sicherlich gewünscht, vor allem aber vorgestellt hatte.

Hierfür waren ebenso historische wie kulturelle oder mentalitätsgeschichtliche Faktoren ausschlaggebend: Die Abfolge von immer neuen politischen und sozialen Revolutionen, die im Fortschrittsmodell nicht eingeplant waren, von ständigen Rückschlägen etwa der Nationenbildung, aber auch eine Reihe von Theorien, die die Freiheit des Menschen allerorten einschränkten, trugen hierzu nicht unwesentlich bei. Insbesondere die Theorien und Lehren der Vererbung, wie sie dann auch der literarische Naturalismus lange vor dem Jahrhundertende aufnehmen sollte, erachteten - wie auch andere philosophische Entwicklungen im Gefolge des Positivismus - „race“, „milieu“ und „moment“ für die Entwicklung des einzelnen Menschen wie der Menschheit insgesamt als ausschlaggebend. Sie sorgten für ein Bewusstsein der Grenzen, welche die Menschheit bereits im 19. Jahrhundert zunehmend in ihre Weltsicht, ja ihre philosophische Weltanschauung aufzunehmen gezwungen war. Schien der Fortschritt zuvor grenzenlos zu sein, so glaubte man nun die Probleme zu erkennen, die gerade auch den Nationen von lateinischer Abkunft drohen könnten. Denn waren nicht die germanischen, waren nicht die angelsächsischen Völker dynamischer, unternehmerischer, unverbrauchter als die kulturell so sehr verfeinerten Romanen? Und war der Niedergang Frankreichs, der unbestrittenen Hegemonialmacht im panlateinischen Lager, nicht symptomatisch für diese Krise der gesamten lateinischen Welt?

Schon lange vor der Veröffentlichung von Max Nordaus einflussreichem Buch über die Dekadenz der ,Rassen' und ihrer entsprechenden Kulturen war die Ansicht einer allgemeinen Dekadenz innerhalb der Menschheitsgeschichte recht verbreitet. Dabei sollten wir nicht vergessen, dass Jean-Jacques Rousseau den Gedanken einer seit dem ,Goldenen Zeitalter' stetig degenerierenden, absteigenden Menschheitsentwicklung gleichsam in den Urgrund der Entwicklung der europäischen Romantik eingeschrieben hatte. Derartige Anschauungen verschafften sich gegen Ende des 19. Jahrhunderts nicht allein in Europa, sondern gerade auch in den Amerikas immer mehr Gehör.

Doch bleiben wir noch für einen Augenblick bei dem erwähnten einflussreichen Band! Unter dem Titel Entartung argumentierte der in Pest geborene Schriftsteller, Arzt und zionistische Politiker Max Nordau, dass die zivilisierten Völker unter dem Ansturm der Barbaren - das Modell wie bei vielen Dekadenzvorstellungen war natürlich das späte Römische Reich - zusammenbrechen würden und so ein neuer Zyklus der Kulturentwicklung seinen Anfang nehmen müsste. Derartige Vorstellungen waren häufig verbunden mit einer extrem gespannten Sinnlichkeit und Empfänglichkeit, verbunden mit der leicht morbiden Faszination für die Kulturen des untergehenden Römischen Reichs. Es war in diesem 
Zusammenhang aufällig, wie stark sich nicht nur die Literatur, sondern auch die Kunst insgesamt an der Orgie, die dem endgültigen Verfall vorausgeht, ausrichtete und wie überzeugend große Maler wie Gustave Moreau oder später Gustav Klimt diese betörenden Sinnenspektakel in Szene zu setzen vermochten. In ihnen brachten sie die Welt des Mythos, des Untergangs Roms - oder mehr noch jenen von Byzanz - in eine unmittelbare Verbindung mit ihren eigenen Kulturen und ihrer eigenen Epoche.

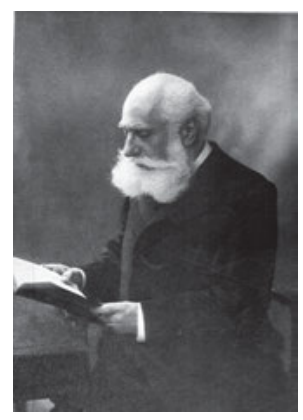

Abb. 71: Max Nordau

(Pest, Kaisertum Österreich, 1849 - Paris, 1923).

Doch zurück zum Diskurs der Entartung und damit zu Max Nordau! Erst mit ihm wurde der Begriff „Fin de siècle“ zu einem Epochenbegriff, indem der aus Ungarn stammende jüdische Essayist, Kulturkritiker und Psychopathologe den Term zum Titel des ersten von insgesamt fünf Büchern seines zweibändigen Werks Entartung machte. Fin de siècle war zugleich Epochenbegriff und Anklage, ja vernichtende Zivilisationskritik, die in ihrer Wirkung auf die zeitgenössische Szene kaum überschätzt werden kann. Denn seit der erste Band von Nordaus Werk im Jahre 1892 erstmals in Berlin erschien, gab es einen ungeheuren Siegeszug des Textes, verbunden mit zahlreichen Übersetzungen insbesondere ins Französische, Englische, Italienische und Spanische, so dass der Begriff der „Entartung“ mit seinen jeweiligen Spielarten überaus weite Verbreitung fand. Nordau wurde zum Bezugspunkt einer finisekulären Sichtweise vom Eigenen wie von dem, was man als ,das Andere' apostrophierte, da in diesem umfangreichen Werk in der Luft liegende Vorstellungen im Zeichen des Wissenschaftlichen so auf den Begriff gebracht wurden, dass es schwer fällt, aus heutiger Sicht dessen Impact in seiner diffusen Tiefgründigkeit überhaupt noch zu verstehen.

In diesem Zusammenhang ist es zum einen entscheidend, dass sich der Arzt Max Nordau dem Forschungsstand der Pathologie und insbesondere der Psychopathologie anschloss, insoweit er auf die Lehren des Franzosen Morel und des zeitgenössisch ja auch für den jungen Fernando Ortiz so wichtigen - italienischen Kriminologen Cesare Lombroso zurückgriff. Bénédicte Auguste Morel hatte bereits in einem berühmt gewordenen Traktat von „dégénérescence“ gesprochen; und 
dieser französischsprachige Begriff stand hinter jenem deutschsprachigen der Entartung, der in der Folge im Nationalsozialismus eine so traurig-bedrückende ,Karriere‘ machen sollte.

Wir müssen es uns an dieser Stelle versagen, der gesamten und schwer überblickbaren Begriffsgeschichte nachzugehen. Wichtig und aufschlussreich aber für uns ist, dass sich nunmehr Zivilisationskritik am Zustand der gesitteten - will sagen: der zivilisierten - Völker im Kleide der Medizin, der Wissenschaft zeigt, genauer: der Psychopathologie. Die Kritik am Verfall der Menschheit ist eine alte Geschichte; doch erst seit Jean-Jacques Rousseau kennen wir eine philosophisch vorgetragene und begründete Kritik an der „dépravation“ des Menschengeschlechts, die deren Gründe in der Zivilisation selbst erblickt. So sahen auch Morel und vor allem Max Nordau den Verfall von Zivilisation und Kultur als Folge einer Krankheit der Zivilisation selbst, als Konsequenz der Kultur. Gleichzeitig wird die Gesellschaft und deren Breite an kulturellen Ausdrucksformen in das grelle Licht der Medizin und damit der Wissenschaftlichkeit getaucht, so dass nun der den Thesen Nordaus zu Grunde liegende und weit ausstrahlende Diskurs ein wissenschaftlicher Bezugsdiskurs ist. Sehen wir uns dies einmal anhand eines ersten Zitats aus dem ersten Buch von Entartung unter der Überschrift Fin de siècle an:

Der Arzt [...], namentlich der, welcher sich besonders dem Studium der Nerven- und Geisteskrankheit gewidmet hat, erkennt in der Fin-de-siècle-Stimmung, in den Richtungen der zeitgenössischen Kunst und Dichtung, in dem Wesen der Schöpfer mystischer, symbolischer, „decadenter“ Werke und dem Verhalten ihrer Bewunderer, in den Neigungen und Geschmacks-Trieben des Modepublikums auf den ersten Blick das Syndrom oder Gesammtbild zweier bestimmter Krankheits-Zustände, mit denen er wohlvertraut ist, der Degeneration oder Entartung und der Hysterie, deren geringere Grade als Neurasthenie bezeichnet werden. ${ }^{5}$

Was uns in dieser eindrücklichen Passage vorgeführt wird, ist im Grunde die Selbstermächtigung eines wissenschaftlich-pathologisch fundierten Diskurses zur Erfassung und Einverleibung kultureller Phänomene in ihrer Gesamtheit und Ganzheit, wobei der künstlerischen Produktion wie auch der Rezeption von Kunst eine besondere pathologische Bedeutung zugewiesen wird. Das naturwissenschaftlich-klinisch-medizinische Erklärungsmuster bemächtigt sich mit Hilfe dieses pseudowissenschaftlichen Diskurses - unter Rückgriff auf die Kronzeugen Morel und Lombroso - einer Welt der Kultur, welcher völlig andere, krankhafte Gesetzlichkeiten unterschoben werden. Es ist ein hochgradig selbstreferentieller

5 Nordau, Max: Entartung. Berlin: Carl Duncker 1899, Bd. I, S. 30 f. 
Diskurs, der im Grunde nicht theoretisch - also experimentell überprüfbar -, sondern ideologisch funktioniert und keinerlei Abweichung kennt, da alles mit Hilfe eines geschulten Blicks von Spezialisten leicht erkannt werden könne. Der nationalsozialistische Diskurs über die sogenannte ,Entartete Kunst" folgt unter Beigabe völkisch-rassistischer Ingredienzien genau diesem Muster.

Der gesamte Bereich der Kultur wird damit an den Maßstäben ,gesund' versus ,krank ${ }^{6}$ gemessen. Es gibt in der Folge nicht nur eine Bezeichnung nach diesen beiden Kategorien, sondern auch Diagnosen und Therapien, denen die Gesellschaft des Fin de siècle - denn auch das Publikum wird in diese ,kranke Kunst ja miteinbezogen - in ihrer Gesamtheit unterworfen wird. Bemerkenswert ist, wie eine ganze Kultur in ihrer Breite unter das Zeichen der Pathologie und damit einer pathologisch relevanten Erklärung gestellt wird.

Der jüdische Arzt und Kulturkritiker hat den Begriff „Entartung“ keineswegs genau so verwendet, wie ihn einige Jahrzehnte später dann die deutschen Nationalsozialisten etwa in Bezug auf die Kunst in ihrer berüchtigten Münchner Ausstellung von 1937 benutzen werden. Und doch fällt es schwer, seine Diagnosen völlig von ihrer späten Nachwirkung abzutrennen. Zu deutlich sind doch jene Beziehungen, welche uns auf den verschiedensten Gebieten darauf hinweisen, dass es mehr oder minder direkte und mehr oder minder subtile und subkutane Beziehungen zwischen dem Fin de siécle - und insbesondere dessen Zivilisations- und Kulturkritikern - einerseits und dem aufkommenden Faschismus und Autoritarismus andererseits gibt. Rassistische oder rassenorientierte Konzepte der Degenerierung und Entartung wurden nicht nur auf ganze Völker - wie etwa das chinesische - angewandt, sondern gegen Jahrhundertende auch auf die eigenen europäischen Gesellschaften ,zuhause‘ appliziert. Dies entspricht der Beobachtung, dass koloniale Unterdrückungspraktiken wie etwa Konzentrationslager oder das Identifizierungssystem des Fingerabdrucks - die beide Kinder des 19. Jahrhunderts sind und auf Kuba, in Südafrika und Indien von Briten und Spaniern entwickelt wurden - bald nicht mehr nur auf koloniale Systeme, sondern auf die kolonialistischen Mutterländer in Europa selbst angewandt werden konnten.

Der Nordau'sche Begriff der Entartung ist freilich nicht antisemitisch gewendet, sondern greift nicht zuletzt jene Künstlerfiguren wie Richard Wagner oder Friedrich Nietzsche an, die schließlich den braunen Machthabern als verspätete Legitimation dienen sollten. Zugleich wird am Beispiel Max Nordaus deutlich, dass bürgerliche Aufsteiger wie er, der lange Zeit in großen europäischen Hauptstädten verbrachte, Spott und Verachtung gegenüber den großbürgerlichen Aussteigern empfand. Denn die Zivilisationskritik bedeutet nicht etwa eine generelle Verdammung der finisekulären Gesellschaft, sondern steht für die Attacke gegen einen besonders prominenten und ,dekadenten` Teil von ihr: die oberen Gesell- 
schaftsschichten, welche - wie die Nazis später sagen werden - vom ,gesunden“ Volkskörper abgetrennt lebten.

Vieles wäre an dieser Stelle über eine Begrifflichkeit zu sagen, die sich aus wissenschaftlicher Sicht alle zu beschreibenden Phänomene wertend einverleibte und einen pseudowissenschaftlichen Diskurs begründete, aus dem es im Grunde als Ideologie kein Entrinnen gab. Mir kommt es bei unseren Überlegungen darauf an, insbesondere die Beziehung zwischen der Kulturkritik und der Zeitstimmung des Fin de siécle aufzuzeigen und deren Potential für die Zukunft zu verstehen. Max Nordaus Kritik, die fest im (Sozial-)Darwinismus verankert ist, stellt gleichwohl keine Ausdrucksform eines Kulturpessimismus dar, sondern dient vielmehr der Manifestation eines Menschen, der durchaus gewissen vitalistischen Grundprinzipien huldigt und die Entartung seiner Zeit als ein Übel ansieht, das bald durch die Selektion überwunden sein werde. Zum anderen bettet sich sein Diskurs ein in einen Kultur- und Fortschrittsoptimismus, von dem die Entartung ja gerade die negativ konnotierte Abweichung darstellt, welche im Sinne des Gesamtwohls der Menschheit ausgeschieden werden soll.

Ich möchte mich an dieser Stelle freilich auf einen zweiten Aspekt dieser Problematik einlassen! Denn es ist aufschlussreich, dass die naturwissenschaftliche Diskursivität - gesegnet mit den Zeichen der Wissenschaft oder besser Wissenschaftlichkeit - sich gerade auf jene Bereiche einließ, die zuvor nicht so leicht in den Bannkreis der Medizin gerückt worden waren: mithin Kunst und Literatur. Auch hierzu sollten wir uns ein Zitat aus Max Nordaus epochemachendem und einflussreichem Buch anschauen:

\begin{abstract}
Alle diese Richtungen, der Realismus oder Naturalismus, der Decadentismus, der Neomystizismus und ihre Unterformen, sind Kundgebungen der Entartung und Hysterie und mit deren klinisch beobachteten und unzweifelhaft festgestellten geistigen Stigmaten identisch. Entartung und Hysterie sind aber die Folge übermäßiger organischer Abnützung, welche die Völker durch die riesenhaft gesteigerten Ansprüche an ihre Tätigkeit und durch das starke Anwachsen der Großstädte erlitten haben. ${ }^{6}$
\end{abstract}

In diesen Formulierungen wird die Kunst und mehr noch der je einzelne Künstler einer Konstatierung krankhafter Strukturen unterworfen, die in ihrer Wertung und dezidierten Ausdrucksfähigkeit keine Zweifel daran lassen, dass fast alle Formen der damaligen zeitgenössischen Kunst unter dieses Verdikt der medizinisch eingefärbten Naturwissenschaften und damit unter Entartungsverdacht fallen. Max Nordaus Buch hat mit seinen Vorstellungen das Fin de siécle in einer ganz entscheidenden Weise mitgeprägt und all jene Elemente und Ideen noch

6 Nordau, Max: Entartung, Bd. 1, S. 79. 
einmal in den neunziger Jahren zusammengefasst, die ohne die vorangehenden Entwicklungen - und zwar unter Einschluss des Naturalismus - nicht denkbar gewesen wären.

Mit Blick auf den Ansatz von Nordau ist wichtig, dass für den jüdischen Kulturkritiker und Arzt diese Entwicklungen letztlich heilbar sind, solange sich die verschiedenen Völker und Individuen gegenseitig unterstützen. Aufschlussreich ist aber auch, dass Nordau davon überzeugt war, dass die degenerativen Erkrankungen letztlich durch darwinistische Selektion wieder verschwinden würden; ein Gedanke, der schon Huysmans' Figur Des Esseintes nicht völlig fremd war. Denn auch letztere war im Zeichen des Naturalismus von bestimmten Vererbungsphänomenen betroffen und schaffte es nicht, ihr Erbgut weiterzugeben, so dass Des Esseintes der letzte in einer langen Reihe von Familienmitgliedern wird, die mit ihm an ihr (wohlverdientes) Ende gelangen. Doch dazu später mehr ...

So löst sich - wie etwa später bei Andrea Sperelli in Gabriele d'Annunzios Roman Il Piacere - ein Problem der Degeneration im Fin de siécle, das unter anderen politischen Vorzeichen wenige Jahrzehnte später mit dem Scheinargument der Rassenhygiene in aller Brutalität angegangen werden wird. Hierbei gilt es zu berücksichtigen, dass Max Nordau selbst Jude war und seine Vorstellungen keineswegs auf die Juden bezog. Vielmehr nahm er gerade jene aufs Korn, die unter dem Banner eines Diskurses segelten, welcher von den Juden als verkommenem, moralisch wie körperlich verfallenem Volk oder einer durch derartige Attribute abgewerteten Rassengemeinschaft sprachen und jenen Antisemitismus pflegten, der in unseren Tagen wieder so schrecklich aktuell ist. Was den ,Fall Max Nordau' so überaus komplex macht ist, dass es schwer fällt, ihm eine wirklich klar antisemitische Stoßrichtung zu unterstellen. Seine Vorstellungen haben gewirkt, aber just bei jenen, die er mit Sicherheit nicht für die Sache der sogenannten ,Entartung‘ begeistern wollte - Kann man ihm dies zum Vorwurf machen?

Ein letzter Punkt ist nicht weniger interessant: Dabei geht es um die Verschmelzung mehrerer Diskurse auf eine sehr charakteristische Weise. Zunächst können wir feststellen, dass wir hier einen medizinisch-pathologischen oder psychopathologischen Diskurs vor uns haben und andererseits einen künstlerisch-literarischen, wobei sich der erstere dem zweiten auflagert und ihn beherrscht: Literatur und Kunst erscheinen nur als Teilbereiche einer klinisch erfassbaren (und letztlich auch therapierbaren) gesellschaftlichen Wirklichkeit. Die Anwendung medizinisch-pathologischer Vorstellungsmuster auf die Literatur hat weder mit Max Nordau angefangen noch hat sie mit ihm aufgehört. Fast zeitgleich beginnt auch Sigmund Freud, ein ebenfalls aus Österreich-Ungarn - um mit Robert Musil zu sprechen: aus Kaukanien - stammender jüdischer Arzt, die Literatur mit den Augen der just von ihm selbst aus der Taufe gehobenen Psycho- 
analyse zu lesen. Auch in diesem Falle ist der wissenschaftliche Diskurs wiederum dem literarischen überlegen, verleibt ihn sich gleichsam ein.

Betrachten wir die Sache von Seiten der Literatur beziehungsweise der Ästhetik her, so sehen wir rasch, dass es gerade der Naturalismus im Gefolge des Zola’schen „Roman expérimental“ war, der sich auf der Suche nach Gesetzmäßigkeiten auf einen medizinisch-pathologischen Diskurs als Garanten des eigenen Schreibens einließ. Er befand sich damit in der Tradition eines Honoré de Balzac, dessen Verankerung der Comédie humaine in naturwissenschaftlichen Diskursen wir gesehen haben. Ohne eine derartige Tradition, die Literatur gleichsam zum Laboratorium der Gesamtgesellschaft macht und auf diese Weise in ersterer Gesetzmäßigkeiten erkennen will, welche auf letztere anwendbar sind, wäre - so scheint mir - eine Vormachtstellung wissenschaftlicher Krankheitsdiskurse gegenüber den spezifisch literarischen nicht möglich gewesen. Die Eigen-Logiken von Literatur als gebündeltem und konzentriertem Lebenswissen wurden in solchen Überlegungen und Versuchen nicht ausreichend berücksichtigt; ein Problem, das Joris-Karl Huysmans mit seiner Verabschiedung vom Naturalismus Zola'scher Prägung - wie wir noch sehen werden - sehr klar erkannte.

Freilich ist die Stoßrichtung nun eine umgekehrte: Wollte die Literatur als Laboratorium Gesetze ermitteln und vorführen, die danach zur Heilung der Gesellschaft beitragen könnten, so versucht nun der medizinisch-therapeutische Diskurs, Literatur und Kunst als Krankheit zu diagnostizieren und zu deren Heilung beizutragen. Die Künstlerin und der Künstler, aber auch ihre Gesellschaften und zumal ihr Publikum erscheinen nun als potentielle Kranke, die ,behandelt' werden müssen. Damit haben wir eine neue Situation in der Verknüpfung zwischen den Diskursen von Wissenschaft und Literatur, die im Fin de siècle überaus produktiv wurde. Wir werden verschiedenste literarische Beispiele dafür kennenlernen.

Der ungeheure Erfolg von Max Nordaus Buch Entartung aber lässt sich nicht ohne jene spezifische Sensibilität des Fin de siècle verstehen, welcher diese Publikation nicht nur entsprach, sondern zugleich auch neue Nahrung gab. In der Tat ist bereits ab dem ersten Kapitel das Grundgefühl einer sich ständig in weitere Verstrickungen begebenden Kultur zu spüren, das zwar bei Nordau keineswegs an seinen Endpunkt gelangt ist, gleichwohl aber unter dem Druck des zivilisatorischen Prozesses - wie es Norbert Elias sagen würde - in einen Prozess zivilisatorischer Krankheiten umgeschlagen ist. Die Zivilisationskrankheiten sind dabei letztlich nur Symptome dieses - wie wiederum Sigmund Freud es später nannte - „Unbehagens in der Kultur“, das wesentlich tiefer reicht und in der Tat auch der Frage nachzuspüren versucht, warum der Mensch eigentlich Literatur schreibt und als Künstlerin oder Künstler die kreativen Künste ausübt. 
Dies hat mit dem Bild des Künstlers als einem Neurotiker oder gar Psychopathen zu tun, beinhaltet gewiss aber auch ein problematisches Menschenbild, in dem die Kunst eigentlich eine marginale Stellung als Ausdrucksform des Menschen einnimmt. Wir könnten im Gegenzug jedoch fragen, ob nicht der Mensch, der nicht nach künstlerisch-kreativen Ausdrucksmöglichkeiten sucht, der eigentlich Kranke und $\mathrm{zu}$ Behandelnde ist. Doch aus Sicht des Verfassers von Entartung ergibt sich eine optimistische Stoßrichtung des Ansatzes: Denn Literatur und Kunst sind heilbar - ganz so, wie nach unserem Dafürhalten ein fehlendes Suchen nach künstlerischen Ausdrucksformen ebenfalls als heilbar angesehen werden könnte.

An diesem Punkt der finisekulären Überlegungen gelangen wir an ein ganz anderes Ende der Literatur, eigentlich an ihr medizinisch-psychopathologisches Ende, insoweit die Symptome der Entartung analysiert, diagnostiziert, in eine Anamnese integriert und schließlich therapiert werden sollen. Am Ende eines solchen Prozesses aber wären die Literaturen in der Tat am Ende: Es gäbe keine Kunst mehr und die Gesellschaft wäre ,gesund‘. Eine eigenartige Vorstellung wäre dies, zu der ein letztes Zitat aus Max Nordaus Entartung passen mag. Nordau bezieht sich dabei, wie Sie gleich sehen werden, auf Literatur und Dichtkunst:

Da haben wir ihn nun, den „Uebermenschen“, den Baudelaire und seine Schüler träumen und dem sie ähnlich zu werden suchen: körperlich krank und schwach, sittlich ein abgefeimter Schurke, geistig ein namenloser Idiot. [...] Ein Schmarotzer der niedrigsten Bildungsstufe [...], müßte er, wenn er arm wäre, elend verhungern, sofern ihn die Gesellschaft in ihrer unangebrachten Güte nicht in einer Idiotenanstalt mit dem Nöthigen versorgen würde. ${ }^{7}$

An diesem Punkt ist der Künstler auf den Hund gekommen: Künstler und Literat sind nun Degenerierte, welche die Gesellschaft eigentlich bloß noch zu ihrem eigenen Schaden durchfüttert und verköstigt. Von hier bis zum Totalangriff auf Künstler, die sich nicht der herrschenden Ordnung und Moral beugen, ist es bloß noch ein kleiner Schritt. Denn die Künstler erscheinen als gesellschaftlicher Auswurf, der schädlich und gefährlich für die Menschheit ist, als nicht mehr nur relativ, sondern unverkennbar absolut Marginalisierte, die es endlich auszumerzen gilt. Ich glaube nicht, dass man derlei Aussagen als bloßen Verbalradikalismus deuten darf: Hier liegt ein Menschenbild zugrunde, für das Kunst und Literatur nicht die höchsten künstlerischen Ausdrucksformen des Homo sapiens sind, sondern gesellschaftlich geächtet werden müssen.

7 Nordau, Max: Entartung, Bd. 2, S. $107 \mathrm{f}$. 
Überdies lassen sich diese Bilder und Vorstellungen in den verschiedensten Bereichen mit dem Aufflammen eines ganz bestimmten Frauenbildes in Verbindung setzen, auf das wir noch zurückkommen werden; das nämlich der schon bei Honoré de Balzac anzutreffenden Femme fatale. Rassismus, Antisemitismus, Sexismus und Misogynie gehen nicht selten Hand in Hand - auch wenn wir Nordau nicht des Antisemitismus verdächtigen wollen. In seiner 1892 erschienenen Schrift hatte der in den wichtigsten Periodika nicht nur in Wien, Berlin, Paris oder London, sondern auch in Buenos Aires und in den USA publizierende Nordau auf Gedanken des Italieners Cesare Lombroso zurückgegriffen und von einer Degeneration gesprochen, welche er in Literatur und Kunst $\mathrm{zu}$ verorten suchte, die aber auch einen genderspezifischen Aspekt beinhaltete. Dies traf den Nerv der Zeit: Nordau stellte die großen Künstlernamen des ausgehenden 19. Jahrhunderts unter dieses der kulturellen Dekadenz biologistisch verwandte Schlagwort der „Entartung“ und verstand es, seine Überzeugung von der Existenz unterschiedlicher menschlicher Rassen mit misogynen Vorstellungen $\mathrm{zu}$ verbinden, welche eine große Breitenwirkung ebenso in der Alten wie in der Neuen Welt erzielten.

Zugleich war sein Rückgriff auf den Mythos ein Zeichen der Zeit. Dabei blieb es nicht bei antiken Mythologien: Im gesamten abendländischen Raum wurden Salammbô und Salome zu den Archetypen der Frauengestalten des Fin de siècle. Derartige Tendenzen lassen sich nicht nur in den Künsten, sondern auch in der Mode erkennen. Auf die so finisekulär drapierte Frau wird dabei die sadomasochistische Funktion der Zerstörerin inmitten berückender Schönheit und der Schönheit totaler Zerstörung im Zugehörigkeitsgefühl zu einer Endzeit, einer untergehenden ,Rasse“ projiziert. Wir alle kennen diese Bilder der Femme fatale, die sicherlich im kulturellen Imaginären unserer Zeit noch immer präsent, wenn auch nicht so vorherrschend wie im ausgehenden 19. Jahrhundert sind.

Die spezifische Situation der gesamten Romania unter Einschluss der Hispanophonie gibt - im Anschluss an Lily Litvak ${ }^{8}$ - keine Rätsel auf und lässt sich in wenigen Worten relativ bündig zusammenfassen: Sie wird erhellt durch eine die gesamte spanischsprachige Welt aufrüttelnde Polemik, die sich im ausgehenden 19. Jahrhundert darüber entzündete, ob die angelsächsische oder germanische Rasse nun endgültig über die lateinische Rasse obsiegt habe. Denn alle Indizien so die Vertreter dieser These - wiesen darauf hin, dass alle großen Erfolge und Fortschritte seit spätestens 1870 deutlich auf Seiten der Angelsachsen beziehungs-

8 Vgl. Litvak, Lily: El sendero del tigre. Exotismo en la literatura española de finales del siglo XIX (1880-1913). Madrid: Taurus 1986; sowie (dies.): España 1900. Modernismo, anarquismo y fin de siglo. Prólogo de Giovanni Allegra. Barcelona: Anthropos 1990. 
weise Germanen lagen und auf Kosten der Romanen gingen. Dies betreffe ebenso den militärischen wie den wissenschaftlichen und zivilisatorischen Bereich.

Gerade das vermeintlich stärkste Land innerhalb der Romania, das sich seit der Mitte des 19. Jahrhunderts im Rahmen der sogenannten „races latines“ selbst in die Rolle der Hegemonialmacht des Panlatinismus gehievt hatte - und nicht umsonst erschien in Paris die einflussreiche Revue des races latines -, war durch die vernichtende Niederlage gegen die preußische Armee 1870 schwer gedemütigt worden. Frankreich schien stellvertretend für die Nationen der Romania, für die Völker lateinischer Abkunft jene Symptome der Dekadenz zu offenbaren, die ein Land charakterisierten, welches noch zu Beginn des Jahrhunderts unter der Führung Napoleons in der Lage gewesen war, Angst und Schrecken über ganz Europa zu verbreiten und dem europäischen Kontinent seinen Stempel aufzudrücken. Über lange Phasen der europäischen Geschichte war es Frankreich gelungen, spätestens seit Beginn des 18. Jahrhunderts die kulturelle und später auch militärische Vorherrschaft zu übernehmen. Noch Mitte des 19. Jahrhunderts besaß Frankreich eine kulturelle Dominanz, welche es als Hegemonialmacht des Panlatinismus eine deutliche Präponderanz über die ehemals spanischen Kolonien Amerikas ausüben ließ, die sich nun innerhalb dieser panlateinischen Idee in der zweiten Jahrhunderthälfte als „Lateinamerika“ zu bezeichnen begannen. ${ }^{9}$

Diese Zeiten - so schien es nun - waren endgültig und unwiederbringlich vorbei. Denn die Niederlage von Sedan war nicht nur La débâcle ganz im Zola'schen Sinne, sie war nicht nur eine militärische „défaite“, sondern weit mehr die Niederlage einer ganzen ,Rasse“, der „race latine“, und alarmierendes Symptom für deren kulturellen, zivilisatorischen, politischen und militärischen Verfall. Demgemäß ist es keineswegs übertrieben, in diesem globalgeschichtlichen Zusammenhang von einem Trauma nicht allein Frankreichs - das dann der Erste Weltkrieg im Revanchismus beseitigen sollte -, sondern der gesamten Romania zu sprechen. Noch heute sind in einer Reihe lateinamerikanischer Länder wie Chile oder Kolumbien die Uniformen und viele andere Details an denen der glorreichen preußischen Armee ausgerichtet - Man kaufte Kanonen bei Krupp. Militärischer Aufstieg und kulturelle Machtentfaltung schienen gegen Ende des Jahrhunderts eine Sache der Germanen und Angelsachsen geworden $\mathrm{zu}$ sein.

Zur Niederlage Frankreichs im Preußisch-Französischen Krieg kam nicht zuletzt die Niederlage Spaniens 1898 im Spanisch-Kubanisch-US-Amerikanischen

9 Vgl. hierzu Jurt, Joseph: Entstehung und Entwicklung der Lateinamerika-Idee. In: Lendemains (Köln) 27 (1982), S. 17-26; sowie Rojas-Mix, Miguel: Bilbao y el hallazgo de América latina: Unión continental, socialista y literaria. In: Caravelle (Toulouse) 46 (1986), S. 35-47. 
Krieg, auf den wir später zurückkommen werden; eine Niederlage, welche die Reste des spanischen Kolonialreichs in Amerika und auf den Philippinen ein für alle Mal beseitigte. Dieses krachende „desastre“, das für Spanien den Verlust von Kuba, Puerto Rico und der Philippinen bedeutete, prägte wiederum nicht allein die Diskussion in Spanien selbst, sondern weit darüber hinaus die längst in Gang gekommene Polemik um die Dominanz der ,Rassen‘. Die Superiorität der Angelsachsen wie der US-Amerikaner und die Inferiorität der lateinischen Völker schienen ausgemacht zu sein. Angesichts dieses „Manifest Destiny“ und der „American Sea Power“ schienen der Untergang der lateinischen Rasse und ihr völliges Verschwinden mitsamt ihrer Kultur und Sprache unmittelbar bevorzustehen - es ist klar, dass die verwendeten Termini wie ,Rasse“ oder ,Volk‘ nicht von mir, sondern aus der zeitgenössischen Diskussion stammen.

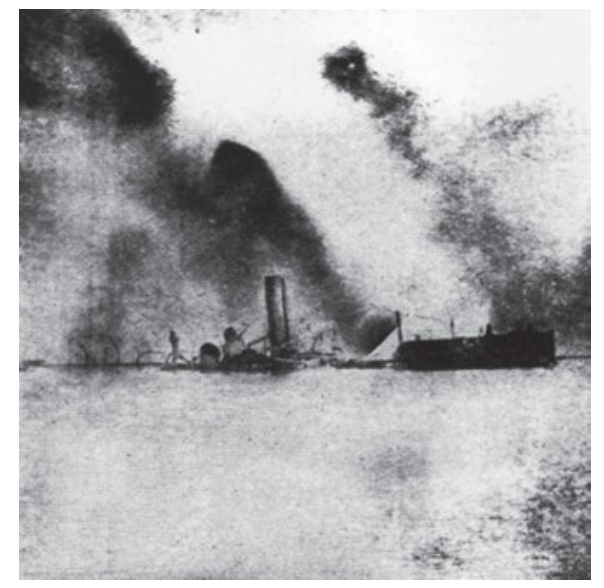

Abb. 72: Brennendes spanisches Kriegsschiff vor Cavite (Philippinen).

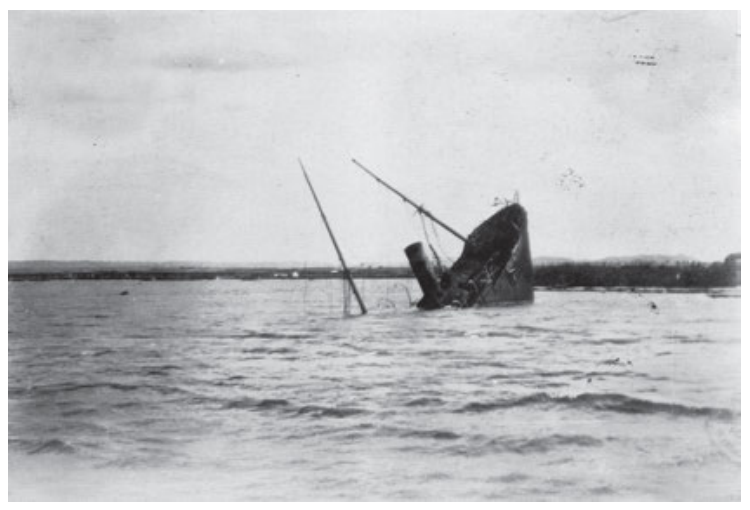

Abb. 73: Versenktes spanisches Kriegsschiff vor Santiago de Cuba. 
Den romanischen Völkern oder - wie man damals sagte - den Völkern lateinischer ,Rasse' gegenüber standen die Angelsachsen, die Germanen oder Teutonen und nicht zuletzt die Slawen, die 1848 ihren ersten Panslawistischen Kongress in Prag einberufen hatten. Der Aufstieg Russlands zum panslawischen Hegemon war eine Frage der Zeit. Die Menschheit in Europa spaltete sich in verschiedene Blöcke auf, von denen einige größere und andere weniger große Zukunftschancen zu haben schienen. Dies ließ im Zeichen einer vom Sozialdarwinismus stark geprägten Welt letztlich die dringliche Frage nach einem Überleben der jeweiligen ,Völker und ,Rassen“ aufkeimen. Wer würde in diesem „Survival of the fittest“ überleben? Die lateinischen Völker schauten am Jahrhundertende angstvoll in die Zukunft.

Wenn wir uns an die aktuellen Diskussionen um den sogenannten „Bruderbund“ der Slawen im Kosowo-Krieg erinnern, sehen wir, dass die damaligen Ideen so ganz ausgestorben nicht zu sein scheinen. Jene alte Aufteilung Europas und der von Europa geprägten Welt gehört zu den Dingen, die nicht mehr sind und doch nicht aufhören können zu sein. Schließlich ist das Konzept der „lateinischen Völker“ in einem Kontext entstanden, der letztlich gerade dem kulturellen Aspekt dieser Völker in einem Panlatinismus entsprang, welcher unter der Führung Frankreichs und im Zeichen des christlichen Kreuzes wie des alten Roms stehen sollte. Es geisterten zum damaligen Zeitpunkt die unterschiedlichsten Rassetheorien durch die Welt, die unter anderem zwischen dem „Homo europeus“, dem „Homo alpinus“ und dem „Homo mediterraneus“ unterscheiden zu können glaubten.

Angesichts der Lächerlichkeit all dieses Rassedenkens und derlei rassistischer Kategorien vergeht einem freilich das Lachen, wenn man an die katastrophalen, furchtbaren Folgen dieses Wahns denkt, der in nicht wenigen Gehirnen - wenn wir diese körperliche Hohlform denn so nennen wollen - bis heute fortspukt! Und doch sind jene Vorstellungen, die mit Gobineau eine deutlich rassistische Dimension erreichten, im 19. Jahrhundert nicht aus dem Nichts gekommen, sondern längst in den Diskussionen der europäischen Aufklärung um die Rassenentwicklung im Kontext des Kolonialismus und in Zusammenhang mit der Schädelkunde, der Kraniologie, sowie mit der Klimatheorie debattiert worden. Kaum ein europäischer Reisebericht des 18. Jahrhunderts, der nicht die Frage nach der jeweiligen Entwicklung der unterschiedlichen Rassen gestellt hätte. Doch dazu wird eine Vorlesung zum Jahrhundert der Aufklärung folgen, die sich mit diesen Fragen auseinandersetzen soll. ${ }^{10}$

10 Vgl. den fünften Band der „Aula“-Reihe in Ette, Ottmar: Aufklärung zwischen zwei Welten (für 2022 geplant). 
Der frankozentrische Panlatinismus, der in zahlreichen Zeitschriften seit Mitte des Jahrhunderts zum Ausdruck kam, erhielt erst seit der Niederlage von Sedan eine so dunkle, düstere Kolorierung. Doch waren in den anderen Rassenkonzeptionen längst Ideologeme vorhanden, die den lateinischen Völkern, den Kulturvölkern des Mittelmeeres, eine vorbestimmte und unausweichliche Degeneration andichteten und angesichts der vorrückenden Macht der „Völker des Nordens“ keine großen Zukunftschancen mehr zubilligen wollten. Der französische Schriftsteller Joséphin Péladan, der Gründer des Ordre de la Rose-Croix Catholique esthétique du Temple et du Graal, schrieb in seinem einundzwanzigbändigen Monumentalwerk über die Dekadenz der lateinischen Rasse, das zwischen 1884 und 1907 in Paris erschien, die so wenig tröstlichen Worte: „Der lateinischen Rasse, die zu sterben verurteilt ist, bereiten wir einen letzten Glanz, um die Barbaren, die kommen werden, $\mathrm{zu}$ blenden und sanfter zu machen. "11 Mit diesen Aussagen des 1908 von der Académie française mit einem Preis für sein Lebenswerk ausgezeichneten Schriftstellers wurde zugleich der Untergang der lateinischen Völker mit einer letzten, alles überstrahlenden Kulturentfaltung am Jahrhundertende gekoppelt. Eine Endzeitstimmung wurde verbreitet, die sich noch ein allerletztes Mal im Vollbesitz der Kräfte der Kultur vor dem letztlich erfolgreichen Ansturm der (angelsächsischen, slawischen oder germanischen) Barbaren glaubte.

Auch der Pangermanismus oder Panteutonismus hatte spätestens seit 1890 an Fahrt aufgenommen und schien durch die koloniale Ausweitung der zunächst zu spät gekommenen Mächte nun die alten lateinischen Kolonialreiche beerben zu können. Der Aufbau eines deutschen Kolonialreichs, das es seit dem brandenburgischen Sklavenhandel nicht mehr gegeben hatte, war in vollem Gange. Wenn wir uns diese weltpolitische und geostrategische Lage vor Augen halten, verstehen wir besser, warum das Fin de siécle keineswegs eine rein europäische Angelegenheit sein konnte, sondern dass hier Kolonialinteressen sowie ehemalige Kolonialreiche und -völker eine höchst aktive Rolle spielen.

Diese Tatsache behinderte freilich den noch immer vorherrschenden Eurozentrismus der Kolonialmächte Europas nur unwesentlich. Entscheidend für unsere Fragestellung ist dabei, dass die oftmals vorwiegend kulturell ausgerichtete Bestimmung des Rassebegriffs gerade in den Diskussionen am Jahrhundertende einen zunehmend rassistischen und sozialdarwinistischen Beigeschmack erhielt, der wesentlich war für die Endzeitstimmung, welche sich zunehmend in den Ländern der Romania ausbreitete. Dass diese Stimmung nicht nur jene des

11 Zitiert nach Litvak, Lily: España 1900, S. 192, FN 1: „A la race latine qui va mourir, nous préparons une dernière splendeur afin d'éblouir et d’adoucir les Barbares qui vont venir.“ 
Jahrhundertendes war, sondern in die Jahrhundertwende hinein wirkte, möge das nachfolgende Zitat belegen.

So verfasste der 1878 in Wien geborene renommierte Publizist und Kulturhistoriker Egon Friedell, der sich 1938 nach dem Einmarsch der deutschen Truppen in Österreich das Leben nahm, einen kleinen Band mit dem Titel Von Dante bis d'Annunzio, der mir einmal vor Jahren bei der Suche nach Literatur zum Fin de siècle in die Hände fiel. Friedell war mir kein Unbekannter, war er doch nach seinem Philosophiestudium Kabarettleiter, Theaterkritiker und Schauspieler gewesen, verfasste Schwänke und Parodien sowie zahlreiche Essays, trat vor allem aber als Autor einer großen, zwischen 1927 und 1932 erschienenen Kulturgeschichte der Neuzeit in drei Bänden sowie einer Kulturgeschichte des Altertums (ab 1936) auf, welche bis heute immer wieder aufgelegt werden. Das schmale Bändchen, das mir eher zufällig in die Hände fiel, war 1915 - also nach Beginn des Ersten Weltkriegs - in Wien und Leipzig erschienen und enthielt gleich im ersten Abschnitt unter dem Titel „Westbarbaren“ die nachfolgend angeführten denkwürdigen Sätze, die ich etwas ausführlicher zitieren darf:

Kriege sind immer geführt worden; und aus allen möglichen und unmöglichen Gründen: um Worte, um Flaggenfelder, um Pfeffer, um Frauen; bisweilen nur, um überhaupt Krieg zu führen. Aber die großen Kriege, die, in denen bedeutsame und geheimnisvolle Kräfte der Vergangenheit und Zukunft sich ausgewirkt haben, sind immer nur aus einem einzigen Grunde geführt worden: sie waren allemal Kulturkämpfe. Kein Krieg jedoch ist jemals so bewußt und deutlich um Kultur geführt worden und nur um Kultur wie dieser jetzige, in dem alle moralischen intellektuellen und physischen Kräfte, die der Mensch besitzt, gesammelt ins Treffen geworfen werden: Millionen Herzen, Millionen Hirne, Millionen Menschengedanken, körperlich geworden in Luft und Feuer, Gold und Erde, Eisen und Licht; und all das einzig und allein, um festzustellen, ob der helle deutsche Gedanke auch fernerhin in Europa siegreich bleiben soll oder nicht.

Der Zweibund kämpft vorläufig gegen sieben Staaten und Völker. Es ist jedoch ziemlich klar, dass einige von diesen kulturell überhaupt nicht in Betracht kommen. Japan ist eine Mottenplage. Menagerievölker wie die Serben und Montenegriner sind vollends indiskutabel. Was jedoch den Rest angeht, so hat sich schon in den ersten Wochen des Krieges das in gewisser Beziehung überraschende Resultat ergeben, dass die Barbarei sozusagen von Osten nach Westen gerutscht ist. Während die Engländer sich als fähig erwiesen, jede Art von Unritterlichkeit, Brutalität und Unehrlichkeit, alle niedrigen und kleinen Kniffe eines unsauberen Geschäftsmannes zur Anwendung zu bringen, während die Franzosen und Belgier eine geradezu bestialische Kriegsführung annahmen, die derjenigen des Balkans in nichts nachsteht, wurden derartige Dinge von den Russen weit seltener gemeldet, und wir haben Grund, anzunehmen, dass es sich auch in den berichteten Fällen um Kosaken und wilde Stämme handelt, die im eigenen Lande nicht wesentlich anders verfahren und bei denen das Brennen und Plündern gewissermaßen noch eine allgemein übliche Verkehrsform ist [...]

Rußland ist ein formloses, schwerfälliges, viel zu großes Untier. Ein gefährlicher, bisweilen aber auch rührender Koloß, der an unheilbarer Fettsucht und Gefräßigkeit leidet, in dessen 


\begin{abstract}
Augen aber doch bisweilen eine Ahnung aufblitzt von der Rätselhaftigkeit alles Geschaffenen und der Güte dessen, der alles geschaffen hat. [...]

Hingegen Frankreich kann nicht mehr gerettet werden. Ein Volk, das niemals, nicht eine Stunde lang, ernst war, das niemals, nicht eine Stunde lang, bescheiden war, ein Volk, das niemals an etwas Höheres geglaubt hat als an Geschlechtsliebe, Lebensgenuß, leere Kunstspielerei und eine billige aufdrapierte Theatergloire, das nicht eine Stunde lang versucht hat, sich selbst ins Antlitz zu blicken, ein Volk, das unfähig ist, weise zu werden, unfähig, gerecht zu sein, unfähig, zu bereuen, das noch auf jede seiner Sünden den Trotz oder das Leugnen gehäuft hat, ein Volk, das an der ärgsten Nationalkrankheit leidet, die es gibt: nämlich an einer geradezu endemischen Verlogenheit, ein solches Volk ist unrettbar verloren. ${ }^{12}$
\end{abstract}

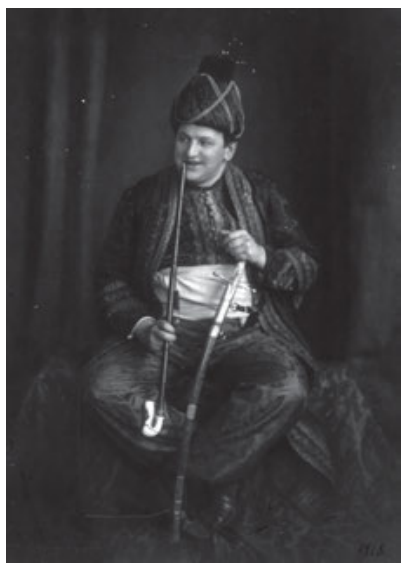

Abb. 74: Egon Friedell (Wien, 1878 - ebenda, 1938).

Ich habe Ihnen diesen schönen Auszug, der bei einem so weltgewandten, belesenen und tiefsinnigen Kulturforscher wie Egon Friedell doch sehr überrascht, aus dem Grunde ausgesucht, weil in ihm jenseits aller damals auf allen Seiten verbreiteten Kriegseuphorie noch vieles jener germanischen und zugleich finisekulären Spiritualität atmet, die sicherlich nicht ganz in den Wirren des Ersten Weltkriegs verloren ging. Diese Formulierungen Friedells machen uns deutlich, dass die Untergangsstimmung nicht notwendig überall und für alle Völker gelten musste, dass aber im germanischen Bereich die Ansicht verbreitet war, dass es mit den Romanen - und allen voran den Franzosen - nicht mehr lange so dekadent weitergehen könne.

Diese Passage erscheint mir deswegen als so bedeutsam, weil jener Krieg, den man im englisch- oder deutschsprachigen Bereich später den Ersten Welt-

12 Friedell, Egon: Von Dante zu d'Annunzio. Leipzig: L. Rosner \& Carl Wilhelm 1915, S. $11 \mathrm{f}$. 
krieg, in Frankreich aber die „Grande Guerre“, den „Großen Krieg“ nennen sollte, uns gegen Ende unserer Vorlesung bei José Enrique Rodó nochmals beschäftigen wird. Zudem schwingt hier zu Beginn des Krieges doch noch viel von jener Kulturbesessenheit mit, welche die Diskussionen am Jahrhundertende so obsessiv charakterisierte. Es handelt sich um eine Deutung der Kulturgeschichte der Menschheit - die Friedell später noch verfassen sollte - aus Sicht eines Kampfs der Kulturen, ganz im sozialdarwinistischen Sinne eines Überlebens der Stärksten, aber auch im Sinne von Samuel P. Huntington. ${ }^{13}$ Letzterer stellt mit seinem kulturterroristischen Erklärungsmodell für keinen geringen Teil der sogenannten ,Think Tanks‘ der US-amerikanischen Präsidenten eine Neuordnung der gesamten Weltpolitik in das Zeichen eines weltweiten Kulturkampfs. Diktion und Stil haben sich geändert; aber sind wir heute wirklich so weit von den Überlegungen des ausgehenden 19. Jahrhunderts entfernt?

Huntington ging davon aus, dass wie beim Kampf im Urwald eben auch Späne fallen, wo gehobelt wird: Dies mag nicht unwesentlich dazu beitragen, eine (neuerliche) Endzeitstimmung zu schaffen. Friedell spielte triumphierend die Karte der eigenen Superiorität, der eigenen kulturellen Überlegenheit. Doch war umgekehrt ein Denken von der eigenen Inferiorität gerade auch bei den sogenannten ,lateinischen Völkern“ verbreitet, wie wir unschwer feststellen können. Am Rande dieser Überlegungen dürfen wir neidlos konstatieren, wie mutig jene Romanisten waren, die wie Viktor Klemperer oder Ernst Robert Curtius nach Ende des Ersten Weltkriegs die Bande zu Frankreich wieder zu knüpfen versuchten; und dies nicht nur in Bezug auf Kultur und Literatur vergangener Jahrhunderte, sondern in Bezug auf die Schriftsteller der damaligen Gegenwart.

Doch kehren wir zurück zu unserem Thema der Dekadenz und der Frage nach einer verbreiteten Endzeitstimmung, und lesen wir dazu den letzten Abschnitt jenes Essays, der dem gesamten Band Von Dante zu d'Annunzio den Titel gab! Denn in diesen fast unglaublichen Formulierungen wird eine Abrechnung mit dem romanischen Geist des Fin de siècle erkennbar, die bewusst auf alle rassistisch eingefärbten Fremd- und Heterostereotype zurückgreift, die bereits am Jahrhundertende im Schwange waren. Ist diese Stelle auch datiert auf Mai 1915, so kommt in ihr doch ein rassistisch eingefärbtes Denken zum Ausdruck, wie es bereits am Jahrhundertende durchaus populär war:

13 Vgl. Huntington, Samuel P.: Der kampf der Kulturen. The Clash of Civilizations. Die Neugestaltung der Weltpolitik im 21. Jahrhundert. Aus dem Amerikanischen von Holger Fliessbach. München -Wien: Europa Verlag 1996. 


\begin{abstract}
Italien, das seit einem Jahrtausend vom Verrat gelebt hat - so gut man eben von einer Lüge leben kann -, das immer und überall Verrat geübt hat, Verrat an allen Menschen und Völkern, an Deutschen und Franzosen, an Päpsten und Kaisern, an Gott und Teufel, Verrat um des Verrats willen, Verrat aus Verräterei, Verrat aus Irrsinn -: Italien ist dazu verdammt, keine Seele zu haben. Der „Geist“ Italiens ist heute verkörpert in einem verkommenen Friseurgehilfen, für den das deutsche Wort „Laffe“ beinahe wie eigens erfunden scheint, und der nun, durch entsprechende Trinkgelder angefeuert, fingerfertig mit seinen ranzigen Pommadentöpfen hantiert.

Italien hat sein Schicksal erfüllt. Es hat seinen historischen Weg vollendet: den unendlich weiten Weg von Dante zu d'Annunzio. ${ }^{14}$
\end{abstract}

Diese Passagen aus Egon Friedells Band belegen, dass die Abwertung der lateinischen Völker weder vor Frankreich noch Italien Halt machte und die philosophisch verankerten Vorurteile eines Jahrhundertendes kolportierte, das die romanischen Länder in voller Dekadenz begriffen darstellte. Diese rassistischen Vorurteile betrafen nicht nur diese beiden europäischen Länder, sondern auch die spanischsprachige Welt Europas einschließlich ihrer ehemaligen überseeischen Kolonien. Die Theorien von Arthur de Gobineaus Essai sur l'inégalité des races humaines und weiterer Vertreter rassistischer Vorstellungen stießen insbesondere in den nordischen Ländern auf offene Ohren, da nicht selten die Dekadenz der mediterranen oder lateinischen Völker dort selbst proklamiert wurde.

Gewiss gab es zeitgleich immer wieder Versuche, umgekehrt die Überlegenheit der lateinischen Völker zu demonstrieren. Es war selbst für so überragende Denker wie José Martí oder José Enrique Rodó nicht einfach, sich in SpanischAmerika vom Druck der in ihren Gesellschaften so stark verbreiteten defätistischen Vorurteile zu befreien und von Reden Abstand zu gewinnen, welche die Länder des spanischen Amerika pauschal als „pueblos enfermos“, als „kranke Völker“ einzustufen versuchten. Bisweilen wurde aber auch als Grund für die Dekadenz die zu starke Verbindung mit der römischen Kirche angegeben. Selbst in Europa kam eine Vielzahl an Theorien auf, die in ernstzunehmenden Wissenschaftszweigen implizit oder explizit eine Unfähigkeit von Anhängern des katholischen Glaubens behaupteten, mit einer Gesellschaft im Zeichen von Fortschritt, Technologie und Entwicklung Schritt halten zu können. Gerade in der deutschen Kultursoziologie verbreiteten sich derartige Ansichten stark und suchten zu erklären, warum die süddeutschen gegenüber den norddeutschen Ländern in ihrer Entwicklung ,zurückgeblieben‘ seien.

All diese Vorstellungen beziehungsweise Ideologien wurden durch die militärischen Niederlagen Frankreichs oder Spaniens nur noch verstärkt, nicht aber

14 Friedell, Egon: Von Dante zu d’Annunzio, S. 60. 
hervorgerufen: Sie hatten sich bereits über einen längeren Zeitraum im 19. Jahrhundert herausgebildet. Im Zeichen der verlorenen Kriege rückten die lateinischen Völker wieder stärker zusammen; eine verständliche Gegenreaktion, die sich ebenso nach der französischen Niederlage von 1870 zeigte wie nach dem spanischen Debakel von 1898 auf Kuba oder den Philippinen. Ein beredtes Beispiel hierfür ist eine Rede des in Spanien über Jahrzehnte überaus einflussreichen konservativen Politikers Cánovas del Castillo aus dem Jahr 1870 - denn er bemerkte grundlegende Verschiebungen im Gleichgewicht zwischen den ,Rassen“:

Wo auch immer man heute hinblicken mag, gibt es mehr als gute Gründe dafür, die germanische Rasse zu beneiden, dass vor ihr erniedrigt die ganzen lateinischen Völker ihre Häupter verbeugen. Zuvor in der gesellschaftlichen Organisation und in den Wissenschaften unterlegen, bildeten das päpstliche Rom und das französische Heer die beiden letzten Bollwerke ihrer einstigen Größe; und die beiden gleichzeitigen Katastrophen, die wir erlebt haben, markieren beide wohl unweigerlich mit dem Siegel der Dekadenz. ${ }^{15}$

In diesen Formulierungen zeigt sich deutlich, in welchem Maße die Gemeinsamkeit des Lateinischen und die Zugehörigkeit zum katholischen Rom eine Einheit der ,gente latina“ geschaffen hatte, welche sich am Jahrhundertende in Katastrophen verwandelte. Diese wurden gemeinschaftlich erlebt, folglich als Niederlagen für die gesamte Gemeinschaft aller panlateinischen Völker empfunden. Die Niederlage Frankreichs angesichts der vorrückenden germanischen Barbaren wurde auch als Niederlage Spaniens eingestanden, das doch eine so hohe Meinung vom Heer der einstmals unbesiegbaren panlateinischen Hegemonialmacht gehabt hatte.

Doch war es 1870 offenkundig geworden, dass das neu entstandene Deutsche Reich im Zentrum Europas die politische Balance aus Sicht der lateinischen Völker ganz deutlich nach Norden und Osten hin verschob. Die weitere politische Entwicklung nach der französischen Niederlage rief die „Commune de Paris“ auf den Plan, die von vielen nicht nur französischen Bürgern als eine gegenüber dem „Aquilon“ noch größere Katastrophe und vor allem als dauerhafte Gefahr durch das aufbegehrende französische Proletariat erschien. All diese Ereignisse verstärkten bei breiten Teilen der Bevölkerung, aber auch bei vielen Künstlern und Intellektuellen ${ }^{16}$ den Eindruck, dass die lateinischen Völker gegen die Angriffe der germanischen und angelsächsischen Barbaren nicht ausreichend gewappnet

15 Cánovas del Castillo: Discurso pronunciado el día 26 de noviembre de 1870. Zit. nach Litvak, Lily: España 1900, S. 160.

16 Vgl. zum aufkommenden Begriff des Intellektuellen im Verhältnis zur Entwicklung in Frankreich Fox, Edward Inman: El año del 1898 y el origen de los „intelectuales“. In: La crisis de fin de 
seien. Konnten sie überhaupt noch den sich abzeichnenden Vorsprung der Völker ,germanischer Rasse‘ auf militärischem, wissenschaftlichem, sozialem und politischem Gebiet einholen? Die Folgen dieser Einschätzung machten sich nicht nur im politischen oder militärischen Bereich, sondern vor allem im gesamten kulturellen Leben bemerkbar.

Im spanischsprachigen Raum setzte sich die Bezeichnung „raza latina“ unter Einschluss Frankreichs durch, wobei diese Idee sich deutlich erst seit 1870 wirklich $\mathrm{zu}$ behaupten vermochte. In Paris etwa erschien nun eine Zeitschrift mit dem Titel Raza latina, wobei wie erwähnt dort schon seit Mitte des 19. Jahrhunderts die angesehene Revue des races latines als Organ des Panlatinismus publiziert wurde. In den unterschiedlichsten Ländern der Romania erschienen plötzlich Zeitschriften, die das Lateinische in ihrem Titel führten. Das Bewusstsein einer gewachsenen Gemeinsamkeit und mehr noch Gemeinschaft bedeutete nicht zuletzt auch für den Bereich der Literatur, dass sich der Austausch und die gemeinsame Diskussion der spezifischen Lage dieser Länder nochmals erheblich verstärkten: Mehr und mehr begriff man sich als Schicksalsgemeinschaft.

Gerade im spanischsprachigen Raum kam nach dem „desastre“ von 1898 die Tatsache hinzu, dass man sich nun beiderseits von den USA und den dominanten Staaten des Nordens als ehemalige Kolonialmacht verachtet und marginalisiert fühlte. Aus dieser Einschätzung heraus entstand eine kritische Reflexion der eigenen kulturellen, sozialen und politischen Entwicklung, die eine neue Literatur, basierend auf einem neuen Konzept der Nation, nicht allein in Spanien heraufführte. So konnte in der Forschung mit guten Gründen ${ }^{17}$ von einer ,Erfindung“ Spaniens durch die sogenannte „Generación del 98“ gesprochen werden; der Neuerfindung eines Landes, das sich in vielerlei Hinsicht aus Europa herausgedrängt fühlte und seine dortige Position neu bestimmen musste. Die Krise prägte die literarischen und kulturellen Anstrengungen nicht nur in Spanien während der letzten beiden Jahrzehnte des Jahrhunderts - also noch vor der definitiven Niederlage des „desastre“ - ganz entscheidend: Die intellektuellen Eliten reagierten schnell.

Spaniens Niederlage von 1898 führte nicht nur in Lateinamerika, sondern auch in verschiedenen romanischen Ländern Europas zu sehr emotionalen Reaktionen. So sprach etwa Gabriele D’Annunzio von einer Invasion der Barbaren, wobei er im Gegensatz zu Egon Friedell diese Unmenschen nicht im Westen,

siglo: ideología e literatura. Estudios en memoria de R. Pérez de la Dehesa. Barcelona - Esplugues de Llobregat: Editorial Ariel 1975, S. 17-24.

17 Vgl. Fox, Edward Inman: La invención de España. Nacionalismo liberal e identidad nacional. Madrid: Cátedra 1997. Vgl. vom selben Autor u. a. La crisis intelectual del 98. Madrid 1976. 
sondern selbstverständlich im Norden und Osten lokalisierte. Auch in Frankreich fielen die Reaktionen sehr intensiv und stark aus, beispielsweise bei Anatole France, der aus einem Salon berichtete, in dem sich gerade die Kunde von der spanischen Niederlage vor Santiago de Cuba verbreitete:

Diese unvermittelte Vision hatte die Seelen traurig gemacht, die Nachricht von einer Flotte, die der Papst gesegnet hatte und welche die Standarte Ihrer Katholischen Majestät trug, einer Flotte, welche die Namen der Heiligen Jungfrau und der Heiligen nach vorne trug, und die nun hilflos war, krachend gescheitert, versenkt von den Kanonen dieser Schweinehändler und Nähmaschinenfabrikanten, dieser Häretiker ohne einen König, ohne Prinzen, ohne Vergangenheit, ohne Vaterland, ohne Armee. ${ }^{18}$

Die Indignation, zugleich aber auch die Ohnmacht ist in diesen Formulierungen allenthalben zu spüren; die gesamte Romania begann sich in Zusammenhang mit diesen schlimmen Niederlagen neu zu konstituieren. Am Ausgang dieses Jahrhunderts, das doch mit der Vorherrschaft Frankreichs begonnen hatte, gab es eine Vielzahl an Essays und Buchpublikationen, die sich um die Frage drehten, ob die lateinischen Völker definitiv in eine Dekadenz eingetreten waren, wie lange diese dauern könnte und wie man ihr am besten entgegenwirken sollte. Zugleich war damit nicht selten die Hoffnung verbunden, dass es sich bei der vor allem militärischen Überlegenheit der Angelsachsen und Germanen, denen man zugleich natürlich eine kulturelle Unterlegenheit unterschob, um ein nur kurzes und vorübergehendes Phänomen handeln könnte. An der eigenen kulturellen Überlegenheit zweifelte man nicht, von ihr war man felsenfest überzeugt.

Ohne auf die verschiedensten Begründungen für die jeweilige Superiorität oder Inferiorität im Kontext unserer Vorlesung näher eingehen zu können, ist es doch aufschlussreich, welcher Stellenwert der Katholizität und damit dem Glauben zugewiesen wurde. Nicht weniger aufschlussreich ist die Tatsache, dass diese Diskussion in Spanien bis weit in die zwanziger Jahre des folgenden Jahrhunderts andauerte, etwa bei José Ortega y Gasset in España invertebrada; eine Diskussion, die im Grunde erst vom Spanischen Bürgerkrieg hinweggefegt wurde. Es ist in jedem Falle faszinierend und lehrreich zu beobachten, wie die Diskussion einer möglichen Regeneration, wie sie etwa in Spanien - aber nicht nur dort geführt wurde, über Jahrzehnte hinweg überging in eine Suche nach dem starken Mann. Denn bei einer Krise der nationalen Identität zählen die einfachen Antworten doppelt, welche die Populismen jeglicher Couleur anbieten, so dass die Rettung durch die faschistische Idee als aussichtsreich erschien.

18 France, Anatole: L'anneau d'améthyste. In (ders.): Histoire contemporaine, Bd. III. Paris: Calmann-Lévy 1924, S. 235. 
Denn der Faschismus machte mit seinen klaren Schuldzuweisungen das teilweise verdrängte rassistische Gedankengut wieder flott und versprach, den Dekadenzgedanken durch einen Diskurs nationaler Stärke ein für alle Mal auszurotten. Populismus und Nationalismus gehen stets Hand in Hand und arbeiten mit Exklusionen, mit der Verdrängung eines ,Anderen', der immer wieder neu konfiguriert werden kann. Und an derartigen ,Anderen' herrschte auch nach der Jahrhundertwende kein Mangel: Selbst die Zerstörungen des Ersten Weltkrieges konnten diese Ausgrenzungen und Feindbilder nicht beruhigen.

So manifestiert der Dekadenzgedanke mit der mit ihm verknüpften Inferioritätsthese oder Inferioritätsangst durchaus eine Bewegungsrichtung hin zum Superioritätsgedanken, der eine Militarisierung der Gesellschaft wie der Außenpolitik und mehr noch des Denkens in seinem Gefolge hat. Dies sind Entwicklungen, welche man nicht simpel den finisekulären Autorinnen und Autoren in die Schuhe schieben kann; doch gänzlich von der Ausbildung derartiger Denkmöglichkeiten und Lösungsversuche freisprechen sollte man diese Autoren auch nicht. Die autoritären Systeme in Italien und später in Spanien stehen durchaus in Zusammenhang mit diesem Denken und wurden von einigen der Vertreter des Fin de siècle - etwa D’Annunzio in Italien oder Maeztu sowie teilweise Unamuno in Spanien - zumindest zu Beginn hoffnungsvoll begrüßt.

Dem Pessimismus der letzten Jahre des Jahrhunderts folgte in vielen lateinischen Nationen die Idee einer lateinischen Renaissance, welche sich bald nach der Jahrhundertwende insbesondere in Italien und Spanien ausbreitete. Und schon glaubte man auch erste Anzeichen für eine Dekadenz der angelsächsischen Länder erkennen zu können, so dass man zunehmend Mut hinsichtlich der eigenen Entwicklung zu fassen begann. In beiden europäischen Ländern wurden Zeitschriften und Vereinigungen gegründet, die versuchten, eine Zusammenarbeit zwischen den lateinischen Völkern insgesamt zu verstärken. In Lateinamerika wurde das Phänomen des von José Enrique Rodós Ariel ausgehenden „Arielismo“ $\mathrm{zu}$ einem viele Intellektuelle, aber auch breitere gesellschaftliche Schichten faszinierenden Phänomen, auf das wir nachdrücklich zurückkommen werden: Der Begriff Lateinamerika füllte sich inhaltlich mehr und mehr.

All dies sind für uns Gründe dafür, das Fin de siècle gerade aus dem Blickwinkel der Romania als eine stark wechselseitig bezogene Vielheit verschiedener Sprachen und Kulturen zu verstehen. Schnell war man dabei, die vorgeblich hohe Kriminalitätsrate der Angelsachsen und die aus Sicht der lateinischen Völker fragwürdige Sexualmoral als Zeichen kommender Dekadenz zu interpretieren. Dies ist - um es vielleicht ein wenig verständlicher zu machen - gar nicht so weit entfernt von jenem Bild, das heute von einem Westeuropa im Zeichen der Gender Diversity in autoritären Systemen etwa des Ostens gezeichnet wird. Man könnte all diese umgedrehten Anwürfe aus lateinischer Sicht - so scheint es aus heutiger 
Sicht - als Kompensationsdenken interpretieren. Das „Renacimiento latino“ war jene Strickleiter der Hoffnung, mit deren Hilfe man aus der deprimierenden Stimmung des Jahrhundertendes selbst wieder herauskommen wollte.

Unter dem Druck der vorwärts preschenden rivalisierenden Großmächte entstand eine neue Koalition der lateinischen Völker, wobei ein Konflikt zwischen einem jeweiligen Nationalismus und dem alle miteinander verbindenden panlateinischen Gedanken niemals ganz auszuräumen war. Lassen Sie mich als ein Beispiel hierfür, das zugleich auch die Grenze des Fin de siècle zu markieren versucht, ein Zitat von Rafael Cansinos Assens anführen! Dieser hochgebildete und vielsprachige spanische Essayist, Übersetzer und Literaturkritiker verfasste einen Artikel mit dem charakteristischen Titel Renacimiento latino im Jahr 1905 und deutete damit an, dass das Gefühl der Dekadenz nun effektiv bekämpft werde. Zugleich schlug diese Bewegung der Erneuerung um in eine politische Richtung, welche letztlich auf das autoritäre Regime der Diktatur Primo de Riveras hinauslief und später der faschistischen Diktatur des „Generalísimo“ Franco Vorschub leistete:

Und alle vereint werden wir mit dem altehrwürdigen lateinischen Schwerte, das heute wieder erstrahlt und Verletzungen zufügt, gegen die angelsächsische Invasion kämpfen, welche eine trübe und traurige Erde aus dieser sonnenerfüllten Erde machen will. Die lateinische Rasse wird wiedergeboren, wie ein Gladiator, von ihrem Traume gestärkt. Die Brüder vereinigen sich. Die Brüder sind Adler, Löwen und der orientalische Drache. Und wie in einem apokalyptischen Gesang, mit Gebrüll und Flügelschlag, wollen sie die Welt wissen lassen, dass die lateinische Rasse lebt und noch immer siegreich ist. ${ }^{19}$

Im Grunde - so sehen wir rasch - hat sich so viel nicht verändert: Noch immer greifen die lateinischen Völker zu ihrem lateinischen Schwert, dessen Klinge sie gegen Nationen führen, die mit Hilfe ihrer stählernen Kriegsschiffe und Kanonenboote, ihrer berühmten Steel Navy, gerade erst die aus Holzschiffchen bestehende spanische Flotte vor Santiago de Cuba und den Philippinen im ersten transatlantischen Medienkrieg versenkt hatte..$^{20}$ Doch sind selbst die apokalyptischen Visionen, die in dieser Passage noch immer nicht verschwunden sind, ins Positive gewendet und machen einer Ideologie des letzten Kampfs Platz, der nunmehr siegreich bestritten werden soll. Was die materiellen, militärischen und wissenschaftlichen Grundlagen dieses Kampfs aber sein sollen, bleibt - weitgehend ungeklärt - im Bereich einer starken, verführerischen Rhetorik.

19 Cansinos Assens, Rafael: Renacimiento latino, zitiert nach Litvak, Lily: España 1900, S. 175. 20 Vgl. das dem Spanisch-Kubanisch-US-Amerikanischen Krieg gewidmete Kapitel in Ette, Ottmar: TransArea. Eine literarische Globalisierungsgeschichte. Berlin - Bosten: De Gruyter 2012, S. $161-220$ 
Wir verstehen auf dieser Grundlage den panlateinischen Geist besser, der unter anderem dazu führte, dass der lange Jahre in Paris lebende Gabriele d'Annunzio von Franzosen wie Italienern als Repräsentant wie Garant des künftig siegreichen lateinischen Geistes gelesen und verstanden werden konnte. Dies ist ein weiter Weg und eine große Wegstrecke entfernt von jener Brücke, welche Egon Friedell zwischen Dante und D’Annunzio konstruiert hatte. D’Annunzio als Vertreter der lateinischen Wiedergeburt: Kaum eine Rolle konnte dem extravaganten italienischen Schriftsteller lieber sein! Und auch bei ihm waren die Beziehungen zum Faschismus und zum italienischen „Duce“ offenkundig.

Halten wir jedoch an dieser Stelle fest, dass derlei Grenzziehungen nicht notwendig immer unter dem Begriffspaar lateinische versus angelsächsische Kultur oder ,Rasse“ verhandelt wurden! Denn häufig war dieser Gegensatz auch mit Hilfe der Opposition zwischen dem mediterranen Licht und den Nebeln des Nordens konstruiert worden; eine Antinomie, die uns spätestens seit Germaine de Staël vertraut ist und selbst bei Denkern und Schriftstellern wie Albert Camus noch allgegenwärtig scheint. Die aufgeregte Debatte um die materielle Überlegenheit der Angelsachsen und die Dekadenz der lateinischen Völker stellt ein Phänomen dar, ohne dessen Einbeziehung wir die folgenden Überlegungen, die spezifisch ästhetischer beziehungsweise literarischer Natur sind, nicht adäquat verstehen könnten.

Dass wir in den nachfolgenden Kapiteln Fragestellungen aufnehmen wollen, die aus der Philosophie an die Literatur herangetragen wurden, oder welche die Literatur in Rückgriff auf die Philosophie aufnahm und weiterentwickelte, hatten wir bereits erwähnt. Die hierfür vorrangig in Betracht kommenden Philosophen sind zweifellos Arthur Schopenhauer, Friedrich Nietzsche und Henri Bergson, deren Denken das Fin de siècle zwischen zwei Welten entscheidend mitprägte.

Der von Arnold Hauser als verbreitet konstatierte Intellektualismus der Jahrhundertwende manifestierte sich auch darin, dass sich die Literatur nicht in den Bereich des Ästhetischen zurückzog - wie man mit einem voreiligen Blick auf das Fin de siècle vielleicht annehmen könnte. Vielmehr suchte sie gerade im geistigen Bereich Antworten auf intellektuelle Herausforderungen, welche die rasche wirtschaftliche Entwicklung des Kapitalismus, die Beschleunigung des technischen Fortschritts und die rasante Veränderung aller Lebensbereiche an Individuum wie Gesellschaft stellten. Aus diesen Gründen kam dem literarischen Essay keine geringe Rolle innerhalb der Literaturen des Jahrhundertendes $\mathrm{zu}$, wobei freilich areale beziehungsweise nationale Eigenarten besonders zu beachten sind. Denn dominant ist der literarische Essay gerade in jenen Ländern, welche im Bereich spezialisierter Philosophie eher ein Manko aufzuweisen haben. Denn dort - und dies betrifft gerade die spanischsprachigen Nationen ebenso in Europa wie in den Amerikas - verlaufen die Grenzziehungen zwischen Literatur und Phi- 
losophie anders als in den stärker spezialisierten Wissens- und Wissenschaftssystemen der Staaten Nord- und Mitteleuropas wie auch Nordamerikas, wo sich unter dem Druck kapitalistischer Entwicklung stärker arbeitsteilige Universitätssysteme einschließlich ausdifferenzierter akademischer Philosophien ausgebildet hatten.

Dass wir hier im Bereich der Philosophie durchaus auch Beziehungen zur zeitgenössischen Psychologie und insbesondere zur Psychoanalyse vorzustellen versuchen werden, hat mit diesen übergeordneten Fragestellungen und der Offenheit von Literatur und Literaten für derartige Herausforderungen theoretischer und philosophischer Natur zu tun. Denn die Literatur ist stets in der Lage und bereit, unterschiedlichste Diskurse und Wissensformen $\mathrm{zu}$ integrieren und als entsprechend in Szene gesetzte ,Stimmen' in ihr polysemes und viellogisches Spiel zu verwandeln.

Dies wirft unweigerlich ein Licht auf die Rolle der Intellektuellen, auf ihre spezifische Funktion innerhalb der sich neu herausbildenden Gesellschaften. Dabei dürfen wir an dieser Stelle schon einmal darauf verweisen, dass der Terminus ,intellectuel“ in einem modernen Sinne just in jenen Jahren geprägt wurde, also gleichsam ein Ergebnis von Konflikten, Auseinandersetzungen und Rollenbestimmungen im Fin de siècle ist. Wir sollten die Jahrhundertwende also keinesfalls in die Mottenkiste des Ästhetizismus und der Weltfremdheit stecken: $\mathrm{Zu}$ vielschichtig sind ihre Aktivitäten.

Sie wissen bestimmt, dass die eben erwähnte Bezeichnung „intellectuel“ in Frankreich sowie im Kontext der sogenannten Dreyfus-Affäre ${ }^{21}$ entstand und von dort ihren terminologischen Siegeszug durch die Kulturen der Welt antrat. Keine Betrachtung einer wie auch immer definierten Struktur der Öffentlichkeit und der öffentlichen Meinung kommt ohne den Begriff des „Intellektuellen“ aus. Damit wird erkennbar, dass nicht nur spezifisch Frankreich - mit seiner sehr eigenen Tradition seit Voltaire - ein besonderes Gewicht in der Frage nach der Beziehung zwischen den Gebildeten und der Gesellschaft zukommt. Vielmehr wird zudem deutlich, dass auch Minderheiten in diesem Spiel mit dem Raum der Öffentlichkeit eine herausragende Bedeutung besitzen - wie etwa die soziale Relevanz

21 Vgl. aus der gewaltigen Forschungsliteratur zum Thema u.a. das der Dreyfus-Affäre gewidmete Kapitel in Jurt, Joseph: Sprache, Literatur und nationale Identität. Die Debatten über das Universelle und das Partikuläre in Frankreich und Deutschland. Berlin - Boston: Walter de Gruyter 2014; sowie ders.: Politisches Handeln und ästhetische Transposition. Proust und die DreyfusAffäre. In: Maas, Edgar / Roloff, Volker (Hg.): Marcel Proust. Lesen und Schreiben. Frankfurt am Main: Insel Verlag 1983, S. 85-107; sowie (ders.): L'engagement de Zola pour Dreyfus et la logique du champ littéraire. In: Dezalay, Auguste (Hg.): Zola sans frontières. Actes du colloque international de Strasbourg (mai 1994). Strasbourg: Presses Universitaires de Strasbourg 1996, S. 33-45. 
der Juden für die öffentlichen Debatten im Rahmen der Dreyfus-Affäre und sich anschließender gesellschaftlicher Auseinandersetzungen in Frankreich.

Typisch finisekuläre Autoren wie Léon Bloy haben sich diesbezüglich mit Publikationen und Essays eindrucksvoll engagiert, standen in diesem Zusammenhang doch nicht zuletzt auch religiöse Fragen im Kontext des sich anbahnenden „Renouveau catholique“ oder besser: einer Hinwendung zu Glaubensfragen auf der Tagesordnung. Aber auch Autoren, die zuvor nicht unbedingt nachdrücklich in die politischen Entwicklungen ihrer französischen Gesellschaft eingegriffen hatten - wie etwa die bereits erwähnten Schriftsteller Anatole France oder Marcel Proust - nahmen plötzlich an derartigen Debatten regen Anteil: Sie engagierten sich, wie man spätestens seit Sartre sagen würde, gesellschaftlich, griffen ins politische Feld aktiv ein.

Ich kann an dieser Stelle leider nicht näher auf die Dreyfus-Affäre eingehen: Sie wirft ein Schlaglicht auf gesellschaftliche Formen einer Neubildung politischer Öffentlichkeit, die uns in ihren Auswirkungen, die bis heute zu spüren sind, interessieren sollten. Vergessen sei jedoch nicht, dass dies auch die Jahre des entstehenden und sich institutionalisierenden Zionismus sind, auf den wir am Rande bereits bei Max Nordau, einem engen Vertrauten und Weggefährten Theodor Herzls, gestoßen waren. Unter Herzls treibender Kraft versuchte der jüdische Zionismus, die Lehren aus einer jahrhundertelangen und letztlich gescheiterten Bemühung der Juden um Assimilation zu ziehen. Dies war nötig angesichts der starken Anfeindungen und Diskriminierungen, denen sie im nationalistischrevanchistisch gesinnten Klima der Troisième République und verstärkt seit Beginn der Dreyfus-Affäre ausgesetzt waren. Auch hier wäre natürlich zu fragen, inwieweit Bücher mit so weitreichenden Folgen wie Edouard Drumonts La France juive, auf das Léon Bloy mit einer Essaysammlung Le salut par les juifs zu antworten versuchte, zeittypische Erscheinungen darstellen, die sehr wohl auch direkte oder indirekte Aussagen über die Verfassung und Entwicklung der Kultur in der Romania des ausgehenden 19. Jahrhunderts erlauben. Das für mich berührendste literarische Zeugnis aus jener Epoche ist Albert Cohens Jour de mes dix ans, das den zehnten Geburtstag des kleinen Juden in Marseille im zeitgenössischen antisemitischen Klima der Dreyfus-Affäre schildert.

Die ausgehenden Jahrzehnte des 19. Jahrhunderts sehen die unterschiedlichsten Formen gesellschaftlichen Protests entstehen, ja sogar eine Weiterentwicklung dieser Formen in den Öffentlichkeiten der romanischen Länder. Der Widerstand gegen die bürgerlich-kapitalistische Gesellschaft oder schlicht auch gegen das Bürgerliche und Philisterhafte zeichnet sich in den unterschiedlichsten Formen ab und erweist sich gerade in der Formierung sozialistischer Organisationsformen einerseits und der Herausbildung anarchistisch-individualistischer Reaktionsformen andererseits als überaus produktiv und spannend. Dabei bilden sich in 
Spanien wie den lateinamerikanischen Gesellschaften jeweils spezifische Ausprägungen etwa des Anarchismus aus, welche wir freilich im Rahmen dieser Vorlesung über die Literaturen des 19. Jahrhunderts nicht mehr behandeln müssen.

Im Kontext divergierender Moderne-Konzepte sucht der Intellektuelle, sich auf unterschiedlichste Weise in die zeitgenössischen Entwicklungen einzubauen. Er versucht mehr noch eine neue, führende Rolle innerhalb der gesamtgesellschaftlichen Entwicklungen zu übernehmen. Dies erfolgte in Lateinamerika ebenso wie in Frankreich, aber auch in Italien und Spanien, wobei im letztgenannten Land gerade dem Anarchismus und Anarchosyndikalismus - bis zu Zweiter Republik und Spanischem Bürgerkrieg - eine große Bedeutung zukam. ${ }^{22}$ Dabei wird uns stets die Frage begleiten, welche gesellschaftlichen, politischen, ästhetischen und literarischen Formen der Protest innerhalb und außerhalb der von uns analysierten Texte annahm.

Ein weiterer, damit zusammenhängender Themenbereich ließe sich vielleicht unter der Überschrift „Selbstbilder und Fremdbilder“ zusammenfassen. In diesem imagologischen Bereich gibt es den im Fin de siècle sofort ins Auge springenden Bereich der Selbstbilder, die in den Texten transportiert und präsentiert werden, und mehr noch jenen bewusster Selbst-Stilisierungen, die sich ebenso im Text als auch textextern leicht finden lassen. Die vielleicht herausragende, in jedem Falle schillerndste Figur ist die des Dandy, auf dessen Geschichte wir kurz eingehen wollen, waren wir doch bei Honoré de Balzac, vor allem aber bei Charles Baudelaire bereits auf diese literarische wie reale Gestalt gestoßen. Den Dandy Baudelaire gab es freilich nur, solange er vom Erbe des Vaters nach Herzenslust leben und herunterbeißen konnte.

In diesem Zusammenhang werden wir vor dem Hintergrund unserer Fragestellung bereits jetzt erkennen können, dass der Dandyismus sich als eine Reaktionsweise verstehen lässt, die zusammen mit anderen Formen als Protest gegen die herrschende Gesellschaft und deren kapitalistisches Wirtschaftssystem verstanden werden kann. Ausgehend vom Bourdieu'schen Begriff des Habitus ${ }^{23}$ ließe sich fragen, was die öffentliche Präsentation eines gegenläufigen Lebensstils im Umfeld von Kunst, Literatur und Künstlichkeit bewerkstelligt und welche soziale Rolle und Funktion dieser aufreizenden Selbstinszenierung zukommt.

22 Vgl. Asholt, Wolfgang: Die Literatur und der Spanische Bürgerkrieg: Modell oder Verlorene Illusionen des Engagements? In: Asholt, Wolfgang / Fähnders, Walter / Reinecke, Rüdiger (Hg.): Uptherepublic. Literatur und Medien im Spanischen Krieg (1936-1939). Bielefeld: Aisthesis Verlag 2006, S. 7-12.

23 Vgl. Bourdieu, Pierre: Der Habitus als Vermittlung zwischen Struktur und Praxis. In (ders.): Zur Soziologie der symbolischen Formen. Frankfurt am Main: Suhrkamp 1974, S. 125-158. 
Die Selbststilisierung des Dandy, die sich in Frankreich auf finisekuläre Weise bereits bei Baudelaire finden lässt, entwickelt und verfeinert sich im Verlauf des 19. Jahrhunderts weiter, bis hin zu jenen Gestalten (und Praktiken), die Marcel Proust in $A$ la recherche du temps perdu unvergesslich in Szene setzen wird. Zugleich stoßen wir an dieser Stelle erneut auf das Phänomen des „Bohémien“, wobei wir unter Rückgriff auf Arnold Hauser eine dreifache zeitliche Gliederung dieses Phänomens erkennen können. Dabei war eine erste Phase die der romantischen Bohème, in welcher dem Künstler stets die Rückkehr in die bürgerliche Gesellschaft offenstand. Diese Art Bohème ist später verherrlicht und idealisiert worden zu einem Zeitpunkt, als sie sich längst entscheidend verändert hatte. Hauser unterscheidet hierbei eine naturalistische von einer impressionistischen Bohème, wobei ich gestehen muss, dass mir dies nicht so ganz einleuchten will.

Festhalten aber können wir, dass die Bohème zunehmend radikaleren und existentielleren Charakter annahm, so wie dies das Künstlerleben eines Paul Verlaine oder Arthur Rimbaud, eines Henri de Toulouse-Lautrec oder Paul Gauguin charakterisiert, und dass der Bohemien sich in einer Protesthaltung gegenüber der bürgerlichen Gesellschaft befand, nur dass dieser Protest aus einer anderen Position als jener des Dandy vorgetragen wurde. Dandy und Bohemien sind häufig als Gegenspieler oder Gegensätze dargestellt worden; und in der Tat kann es auf Ebene des Habitus kaum einen größeren Gegensatz geben als den zwischen der äußersten Raffinesse in Kleidung und schönem ästhetischen Schein, wie wir ihn beim Dandy finden, und jener radikalen Verwahrlosung, wie sie Kleidung und Lebensformen des Bohemien kennzeichnet.

Doch beide verbindet der Protest gegen eine bürgerliche Welt- und Kleiderordnung, gegen eine von der Bourgeoisie und der rational gefügten bürgerlichen Gesellschaft auferlegte Disziplinierung des Lebens bis hin in die strenge Zeitverwendung, gegen die Dandy und Bohemien - der eine als aufgestiegener Bürger oder Aristokrat, der andere als deklassierter, auf die Ebene des Proletariats abgesunkener Künstler - nachhaltig protestieren. Wir werden auf diese Thematik verschiedentlich zurückkommen, sehen aber bereits zum jetzigen Zeitpunkt, wie stark sie mit der Selbststilisierung und Verwandlung des Lebens in ein Kunstwerk zu tun hat. Mit dieser Transformation des Lebens in eine „EFuvre d'art“ wird zugleich eine Problematik erfasst, welche die Grenzen zwischen Kunst und Leben möglicherweise neu bestimmt; Fragestellungen also, die in einem anderen zeithistorischen Kontext nicht zuletzt die Dadaisten wie die historischen Avantgarden überhaupt beschäftigten.

Bevor wir uns konkret den literarischen Texten des Fin de siècle zuwenden, möchte ich Ihnen gerne einen kleinen Text präsentieren, der Ihnen zeigen mag, dass das Phänomen des Dandy keineswegs ein finisekuläres und des Weiteren auch kein notwendig sehr entferntes ist. Denn wir finden etwa in dem vierbän- 
digen Reisewerk des Hermann Fürst von Pückler-Muskau, den Sie ja durch eine Reihe kultureller Errungenschaften kennen, einen auf London, den 7. Juni 1827 datierten Brief, in dem man uns ganz einfach klarmacht, was ein Dandy so ist und was er in der britischen Hauptstadt so alles braucht. Das Phänomen Dandy, das wissen wir spätestens seit Balzac, durchzieht das 19. Jahrhundert, wenn es seinen Höhepunkt auch in den ausgehenden Jahrzehnten dieses Jahrhunderts findet:

Als ein Beispiel, was ein Dandy hier alles bedarf, theile ich Dir folgende Auskunft meiner fashionablen Wäscherin mit, die von einigen der ausgezeichnetsten Eleganz emplovirt wird, und allein Halstüchern die rechte Steife, und Busenstreifen die rechten Falten zu geben weiß. Also in der Regel braucht ein solcher Elegant wöchentlich 20 Hemden, 24 Schnupftücher, 9 bis 10 Sommer-„Trowsers“, 30 Halstücher, wenn er nicht schwarze trägt, ein Dutzend Westen, und Strümpfe à discrétion. Ich sehe Deine hausfrauliche Seele von hier versteinert. Da aber ein Dandy ohne drei bis vier Toiletten täglich nicht füglich auskommen kann, so ist die Sache sehr natürlich, denn

1) erscheint er in der Frühstücks-Toilette im chinesischen Schlafrock und indischen Pantoffeln.

2) Morgentoilette zum Reiten im frock coat, Stiefeln und Sporen.

3) Toilette zum Diné, in Frack und Schuhen.

4) Balltoilette in Pumps, ein Wort, das Schuhe, so leicht wie Papier, bedeutet, welche täglich frisch lackirt werden [...].

Um 6 Uhr kam ich zu Hause und schreibe Dir noch, während man schon meine Laden schließt, um mir eine künstliche Nacht zu bereiten. Die Kammerdiener haben es hier schlimm, und können nur, so zu sagen: aus der Hand schlafen, oder wie die Nachtwächter am Tage. ${ }^{24}$

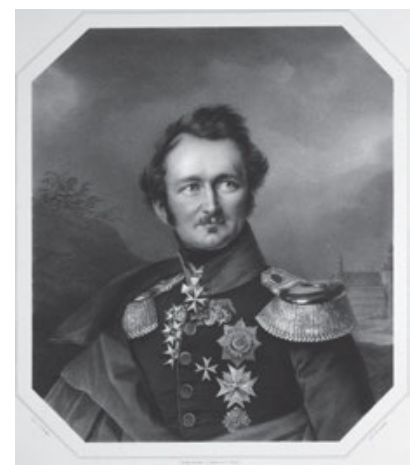

Abb. 75: Hermann von Pückler-Muskau (Schloss Muskau, Landkreis Görlitz, 1785 - Schloss Branitz, Cottbus, 1871).

24 Pückler-Muskau, Hermann Fürst von: Briefe eines Verstorbenen. Ein fragmentarisches Tagebuch aus Deutschland, Holland und England, geschrieben in den Jahren 1826, 1827 und 1828. 4 Bde. Stuttgart: Hallberger 1831, Bd. 4, S. 48 f.: Brief vom 7. Juni 1827. 
Damit wird uns klar, wie wichtig Inszenierung und Selbstinszenierung sind; und zugleich wirft dies ein bedeutsames Licht auf Theatralität überhaupt, und zwar in Form des bürgerlichen oder nicht-bürgerlichen Theaters, wo sich bekanntlich nicht nur die Schauspielerinnen und Schauspieler, sondern auch das Publikum gebührlich in Szene zu setzen weiß. Es geht um die Inszenierung menschlicher Körper als Kunstartefakte; um deren Gestaltung zu Körper-Objekten, die mit allen Sinnen, vom Visuellen bis zum Olfaktischen, wirken sollen und zugleich eine Geschlechtlichkeit in Szene setzen, welche es komplex zu dechiffrieren gilt.

Doch von den Selbstbildern ist es nur ein kleiner Schritt zu den Fremdbildern. Dabei interessieren uns vor dem Hintergrund von Fragen der Geschlechtlichkeit insbesondere Frauenbilder, die im Fin de siècle entstehen beziehungsweise projiziert werden. Auch hier könnte man wie beim Pärchen Dandy/Bohemien von einer Zweiteilung ausgehen, deren erster Teil bereits erwähnt wurde: die sogenannte Femme fatale, die männermordende Schönheit, die ebenso anziehend wie zerstörerisch wirkt.

Mario Praz hat in seiner klassischen Studie über Liebe, Tod und Teufel ${ }^{25}$ dieser Figur unter dem Titel der „Belle Dame sans merci“ gedacht. So sehen und verstehen wir, dass auch die Femme fatale - ebenso wenig wie Dandy und Bohemien - eine Schöpfung der Jahrhundertwende ist, sondern auf wesentlich längere Traditionsstränge verweist. Der Übergang von der Romantik zum Jahrhundertende ist, wie wir schon mehrfach sahen, kein harter Bruch, sondern eine Epoche der schleifenden Schnitte, der sachten und gleichwohl entschiedenen Übergänge, die wir - so hoffe ich - überzeugend mit Charles Baudelaire und Arthur Rimbaud als Figuren ansetzten, die eine neue (nicht nur) literarhistorische Epoche einläuteten.

Wir werden uns mit dieser insbesondere die Männerwelt beeindruckenden Femme fatale in Literatur und Kunst des Jahrhundertendes ausführlich beschäftigen, zugleich aber - wie dies schon Hans Hinterhäuser tat ${ }^{26}$ - kontrastiv auf die schöne, zerbrechliche, unberührte und unschuldige Frau beziehen, die gleichsam den Gegenpol des finisekulären Frauenbildes darstellt. Dieses wird uns - ähnlich wie Dandy und Bohemien - tiefe Einblicke nicht nur in die Dekolletés der Damenwelt und damit in die sexuellen Praktiken der Jahrhundertwende gewähren, sondern mehr noch Einsichten in die Zusammenhänge zwischen Sinnlichkeit und Schreiben vermitteln, welche für eine Vielzahl von Autorinnen und Autoren dieser Epoche grundlegend waren.

25 Vgl. Praz, Mario: Liebe, Tod und Teufel. Die schwarze Romantik. Mit 16 Bildtafeln. München: Deutscher Taschenbuch Verlag ${ }^{4} 1994$.

26 Vgl. Hinterhäuser, Hans: Fin de siècle. Gestalten und Mythen. München: Fink 1977. 
Das Fin de siècle steht im Zeichen der Synästhesien: Es ist diese Entdeckung der Sinnlichkeit und mehr noch ihre radikale Steigerung in der finisekulären Literatur, welche die Zeitgenossen und uns Heutige noch beeindruckt. Diese ästhetische Eindrücklichkeit blieb selbstverständlich nicht auf die Literatur beschränkt, sondern erstreckte sich nicht weniger auf das Gebiet aller finisekulären Künste. Denken Sie noch einmal an unser synästhetisches Erleben der Oper von Richard Strauss in der vorangegangenen Vorlesung zurück! Wir werden sogleich zu untersuchen haben, in welcher Beziehung diese Seite des Jahrhundertausgangs mit den hier skizzierten Problemen und Themenstellungen zusammenhängt - ein Zusammenhang, bei dem im Übrigen die Musik ganz bestimmt nicht fehlen darf. 